\title{
Performance assessment of a membrane liquid desiccant dehumidification cooling system based on experimental investigations
}

\author{
Ziwei Chen, Jie Zhu*, Hongyu Bai \\ Department of Architecture and Built Environment, University of Nottingham, Nottingham, \\ NG7 2RD, UK
}

\begin{abstract}
A membrane-based liquid desiccant dehumidification cooling system is studied in this paper for energy efficient air conditioning with independent temperature and humidity controls. The system mainly consists of a dehumidifier, a regenerator, an evaporative cooler and an air-to-air heat exchanger. Its feasibility in the hot and humid region is assessed with calcium chloride solution, and the influences of operating variables on the dehumidifier, regenerator, evaporative cooler and overall system performances are investigated through experimental work. The experimental results indicate that the inlet air condition greatly affects the dehumidification and regeneration performances. The system regeneration temperature should be controlled appropriately for a high energy efficiency based on the operative solution concentration ratio. It is worth noting that the solution concentration ratio plays a considerable role in the system performance. The higher the solution concentration ratio, the better the dehumidification performance. However simultaneously more thermal input power is required for the solution regeneration, and a crystallization risk in the normal operating temperature range should be noted as well. The system mass balance between the dehumidifier and regenerator is crucial for the system steady operation. Under the investigated steady operating condition, the supply air temperature of $20.4^{\circ} \mathrm{C}$ and system COP of 0.70 are achieved at a solution concentration ratio of $36 \%$.
\end{abstract}


Keywords: Liquid desiccant dehumidification, Membrane-based, Evaporative cooling, Experimental study, System mass balance

* Corresponding author. Tel: +44 1158466141. E-mail address: jie.zhu@ nottingham.ac.uk.

\section{Nomenclature}

Symbols

\begin{tabular}{|c|c|}
\hline$c_{p}$ & Specific heat capacity $(\mathrm{J} / \mathrm{kg} \cdot \mathrm{K})$ \\
\hline$C_{\text {sol }}$ & Desiccant solution concentration \\
\hline$h$ & Specific enthalpy $(\mathrm{J} / \mathrm{kg})$ \\
\hline$\dot{m}$ & Mass flow rate $(\mathrm{kg} / \mathrm{s})$ \\
\hline$m_{\text {float }}$ & Flow meter float weight $(\mathrm{kg})$ \\
\hline$\dot{M}_{\mathrm{a}}$ & Mass addition rate $(\mathrm{g} / \mathrm{s})$ \\
\hline$\dot{M}_{\mathrm{r}}$ & Mass removal rate $(\mathrm{g} / \mathrm{s})$ \\
\hline$P$ & Pressure $(\mathrm{Pa})$ \\
\hline$\dot{Q}_{\text {cooling }}$ & System total cooling output (W) \\
\hline$\dot{Q}_{\mathrm{DH} \_ \text {cooling }}$ & Dehumidifier cooling output power (W) \\
\hline$\dot{Q}_{\mathrm{RE}}$ & Regenerator thermal input power (W) \\
\hline$T$ & Temperature $\left({ }^{\circ} \mathrm{C}\right)$ \\
\hline$T_{\mathrm{wb}}$ & Wet bulb temperature $\left({ }^{\circ} \mathrm{C}\right)$ \\
\hline$T_{\mathrm{w}_{-} \mathrm{f}}$ & Hot water supply temperature $\left({ }^{\circ} \mathrm{C}\right)$ \\
\hline$T_{\mathrm{w}_{-} \mathrm{r}}$ & Hot water return temperature $\left({ }^{\circ} \mathrm{C}\right)$ \\
\hline$U_{\mathrm{X}}$ & Measured variable uncertainty \\
\hline$U_{\mathrm{Y}}$ & Calculated variable uncertainty \\
\hline$v$ & Volumetric flow rate $(\mathrm{L} / \mathrm{min})$ \\
\hline $\bar{V}$ & Average air velocity $(\mathrm{m} / \mathrm{s})$ \\
\hline$V_{\text {float }}$ & Flow meter float volume $\left(\mathrm{m}^{3}\right)$ \\
\hline$X_{i}$ & Measured variable \\
\hline
\end{tabular}


Calculated variable

Greek letters

$\begin{array}{ll}\varepsilon_{\mathrm{DH}} & \text { Dehumidification effectiveness } \\ \varepsilon_{\mathrm{EV}} & \text { Evaporative cooling effectiveness } \\ \rho & \text { Density }\left(\mathrm{kg} / \mathrm{m}^{3}\right) \\ \omega & \text { Humidity ratio of air flow }\left(\mathrm{kg} / \mathrm{kg}_{\text {dryair }}\right)\end{array}$

Subscripts

air

Air

eq Equilibrium condition

in Inlet

out Outlet

S Saturation

sol Solution

w Water

Abbreviations

COP Coefficient of performance

DH Dehumidifier

EV Evaporative cooler

LDD Liquid desiccant dehumidification

LDDC Liquid desiccant dehumidification cooling

MLDD Membrane-based liquid desiccant dehumidification

MLDDC Membrane-based liquid desiccant dehumidification cooling

RE Regenerator 


\section{Introduction}

In the hot and humid region, air conditioning plays an important role in handling both sensible and latent cooling loads. The main design criteria for air conditioning systems are thermal comfort, indoor air quality, energy efficiency and associated environmental effect [1]. Mechanical vapour compression is the most common applied technology, in which dehumidification is accomplished by cooling air to the dew point temperature, and consequently extra energy is consumed to reheat the airstream for the desired supply temperature [2]. It has been reported that energy consumption of an air conditioning system exceeds $50 \%$ of the total energy usage of a building in the hot and humid climate [3]. On the other hand, the associated risks of mechanical vapour compression system such as leakage, bacterial breeding, and fungi due to water condensation on the cooling coil surface, have been noticed with prominent effects on indoor air quality and occupants' health. To address the drawbacks, many innovative dehumidification cooling systems have been developed with efficient independent temperature and humidity controls and simultaneously less energy consumption. Desiccant cooling has been regarded as one of the environmental-friendly air conditioning approaches without overcooling and reheating problems [4]. In theory, desiccants which are classified into solid and liquid materials, remove moisture from an airstream through natural sorption process. Compared with the solid desiccant system, the liquid desiccant dehumidification (LDD) system has been a more promising and economical choice due to its flexibility in utilizing low-grade energy sources [5] and capability of independent humidity and temperature controls [6]. Moreover, the LDD system is capable to provide high quality supply air as liquid desiccants can filter the bacteria, microbial contaminations, viruses and moulds [7]. In terms of energy conservation, $19 \%$ reduction in the annual primary energy consumption could be achieved with an LDD system for an office building in Miami, Florida [8]. Regarding 
to the economical aspect, $40 \%$ of the operation cost can be saved with an LDD system compared to a conventional air conditioning system [9].

Generally, the LDD system performance is influenced by many factors, including liquid desiccant characteristic, packing type and operating condition [10]. For the selection of a liquid desiccant, several parameters should be considered, such as boiling point elevation, energy storage density, regeneration temperature, thermo-physical property, availability and cost [11]. Halide salts are the most commonly selected desiccants, for instance lithium chloride ( $\mathrm{LiCl}$ ), lithium bromide $(\mathrm{LiBr})$ and calcium chloride $\left(\mathrm{CaCl}_{2}\right)$. Among them, $\mathrm{LiCl}$ is mostly preferred due to its favourable equilibrium water vapour pressure in the dehumidification process [12]. Nonetheless, $\mathrm{LiCl}$ solution usually crystallizes at large vapour pressure depression [13]. On the other hand, $\mathrm{CaCl}_{2}$ is regarded as the cheapest and most readily available desiccant. Better mass transfer potential in the regeneration process is obtained with $\mathrm{CaCl}_{2}$ solution compared to $\mathrm{LiCl}$ solution under the same operating condition [14]. Besides, weak organic acid salts such as potassium and sodium formate are good alternatives [7] and ionic liquids become promising for the specific achievable dew point temperature at a comparatively lower driving temperature [13]. With respect to the regeneration of liquid desiccant solution, it can be performed by either heating dilute solution or inlet air to the required regeneration temperature. By comparison, heating dilute solution is proved to be more efficient in the solution regeneration process [15].

The LDD packing arrangement is another critical factor influencing the dehumidification performance [16]. The available packing types are namely, wetted wall, spray tower, packed column and membrane-based, which provide the solution and air flow in different patterns including parallel, counter and cross flows. The wetted wall, spray and packed towers have been popular options for the dehumidification purpose [17]. However, these direct contact packing types have a major problem of liquid desiccant droplet carryover, which could be 
harmful to occupants' health, building structure and indoor equipment [18]. To eliminate this problem, a membrane-based liquid desiccant dehumidification (MLDD) system is adopted, which involves an indirect contact process for dehumidification. Membranes acting as selective barriers allow heat and moisture transfers between the solution and airstream but prevent the carryover of liquid desiccant solution into the supply airstream [18]. Membranes are categorized into dense and porous types depending on the pore dimension. The dense membrane is hydrophilic for vapour transportation, while the porous membrane with a more open volume and larger pores is hydrophobic [19]. With respect to the form, membranes can be constructed as flat sheets with a simple structure and easy fabrication, or hollow fibres with a large packing density and high effectiveness but a more complex design.

A liquid desiccant dehumidification cooling (LDDC) system is defined as a hybrid air conditioning system combining a liquid desiccant dehumidification unit to handle the latent cooling load and a cooling unit to deal with the sensible cooling load [20]. A variety of cooling technologies can be integrated with the LDD system, such as vapour compression, vapour absorption and evaporative cooling. Among them, the evaporative cooling system has been widely applied because of its lower installation and running costs [21]. Compared with a vapour compression air conditioning system, the reduction in energy consumption of an evaporative cooler is over $75 \%$ [22]. Generally, the evaporative cooling is classified into direct and indirect types. The effectiveness of the direct evaporative cooling system is in the range of $70 \%$ to $90 \%$, while the effectiveness ranges only from $40 \%$ to $60 \%$ for the indirect system. The direct evaporative cooling system adds moisture to the cooled supply air, whereas the indirect evaporative cooling system provides only sensible cooling to the supply air without any moisture being added, which is more preferred in the humid climate [23]. 
The selection of an evaporative cooling unit for an LDDC system depends on climate condition, supply air demand, cost and etc. The feasibility of an LDDC system with an indirect evaporative cooling unit is evaluated by experimental work in [24], in which the indoor air temperature reduces from $33.8^{\circ} \mathrm{C}$ to $22.3^{\circ} \mathrm{C}$ and the relative humidity decreases from $68.6 \%$ to $35.5 \%$. With the similar design concept, a drop of $7.5^{\circ} \mathrm{C}$ in the indoor air temperature is achieved in [25]. In response to the climate condition and air conditioning requirement in Hong Kong, a hybrid liquid desiccant air conditioning system is developed by integrating both direct and indirect evaporative cooling means [26], whose performance is investigated by theoretical modelling. The LDDC system with an evaporative cooling unit is proved with remarkable energy and cost saving potentials [27]. By installing an evaporative-cooling assisted LDDC system for an open office building in Seoul, South Korea, $12 \%$ saving of the annual primary energy consumption could be achieved compared with the conventional air conditioning system [28]. More than 50\% of the lifetime operating cost can be saved with an LDDC system compared to the conventional air conditioning system in Singapore [29]. By utilizing renewable energy in the regeneration process, the LDDC system can be more sustainable and economical, for example the abundant solar energy. Not only solar thermal but also photovoltaic technologies can be integrated into a solar-assisted LDDC system [30]. The feasibility of a membrane-based liquid desiccant dehumidification cooling (MLDDC) system powered by solar thermal energy is proved in [31] with significant economic and environmental benefits.

The MLDDC system has been widely explored through modelling and simulation. For instance, a comprehensive model of a parallel-plate MLDDC system is developed to address the features of the conjugate heat and mass transfer in [32]. Various approaches of integrating an evaporative cooling unit into the MLDDC system result in different system designs and configurations. To overcome the LDDC system shortcomings of complexity and large geometrical size, a compact membrane-based air conditioning system is developed with an 
evaporative inter-cooler unit for building application in [33], whose cooling output is in the range of $570 \mathrm{~W}$ to $1362 \mathrm{~W}$ and the dehumidification effectiveness is in the range of $30 \%$ to $37 \%$ based on the experimental results.

Extensive experimental and theoretical studies have been conducted to investigate the effects of various parameters on the LDDC system performance. For example, the most significant dimensionless parameters affecting the dehumidification performance are identified through theoretical analyses $[8,34]$, which are NTU, solution to air thermal capacity ratio and solution concentration ratio. On the other hand, the experimental investigations in [35-37] demonstrated that the LDDC system dehumidification performance evidently varies with inlet air condition, solution concentration ratio and packing material density. However, limited researches have been carried out to evaluate the effects of operating variables on the MLDDC system performance by experimental work. In this study, a novel MLDDC system is proposed for experimental investigations. The system is featured:

a. Independent controls in the supply air temperature and humidity are achieved in the hot and humid climate without overcooling, reheating and water condensation problems.

b. The carryover problem of desiccant solution droplet into airstream is avoided by adopting the semi-permeable micro porous membranes in both the dehumidifier and regenerator units.

c. An indirect approach is employed to handle the sensible cooling load, where heat transfer takes place between the cool airstream from the direct evaporative cooling unit and the dehumidified airstream.

d. Low-grade heat sources could be utilized to regenerate the liquid desiccant (e.g. in a temperature range of $50.0^{\circ} \mathrm{C}$ to $80.0^{\circ} \mathrm{C}$ for $\mathrm{CaCl}_{2}$ ). 
The system feasibility and performance are evaluated under various operating conditions. The influences of inlet air condition, desiccant solution concentration ratio, hot water and cold water temperatures on the system dehumidification, regeneration, evaporative cooling and overall performances are investigated experimentally.

\section{Experimental Set-up}

\subsection{System description}

The proposed MLDDC system mainly consists of four components: a dehumidifier, a regenerator, an evaporative cooler and an air-to-air heat exchanger, in which four processes are involved as illustrated in Fig. 1:

a. Dehumidification process: the outdoor hot and humid air is dehumidified by liquid desiccant solution in the dehumidifier;

b. Regeneration process: the indoor return airstream passes through the regenerator and absorbs moisture from the dilute desiccant solution;

c. Direct evaporative cooling process: the evaporative cooler lowers the indoor return air temperature through water evaporation;

d. Sensible cooling process: the airstream from the evaporative cooler is used to cool the dehumidified air to meet the desired supply air requirement in the air-to-air heat exchanger.

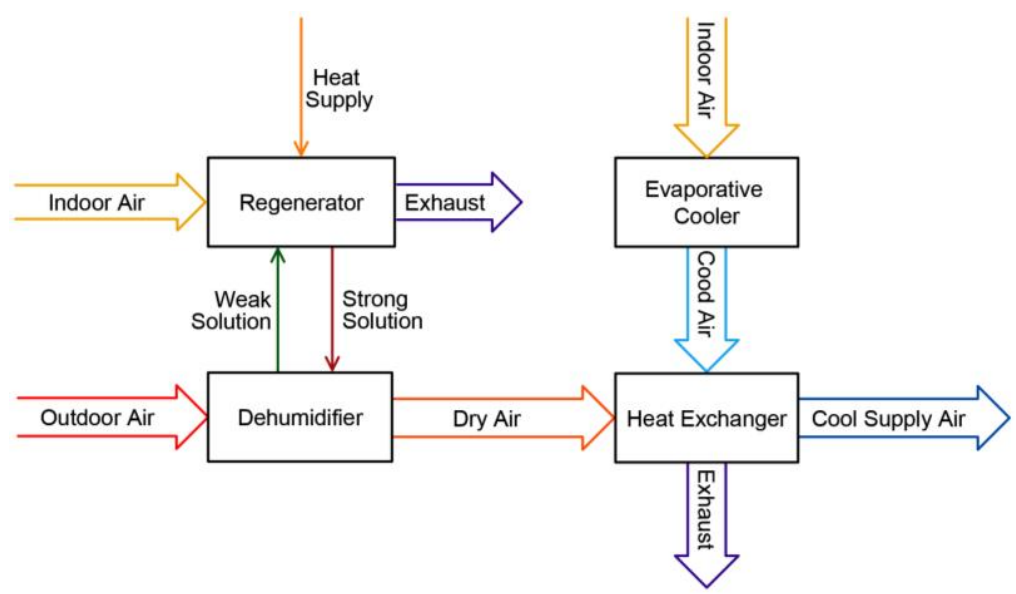

Fig. 1. Block diagram of the MLDDC system 
A labelled schematic diagram of the experimental set-up is presented in Fig. 2. A 3kW boiler is used to provide hot water for the regeneration purpose. Three AC axial fans are fitted in the dehumidifier, regenerator and evaporative cooler respectively. Two $15 \mathrm{~W}$ single phase magnetic-driven pumps are used to circulate the regenerated and dilute desiccant solutions. A liquid-to-liquid heat exchanger (HX2) allows heat recovery between the two solutions. In order to enhance the dehumidification performance, cold water is utilized to cool the regenerated solution prior to flowing into the dehumidifier. Ball valves (V1, V2, V3, and V4) are installed to control the desiccant solution and water flow rates.

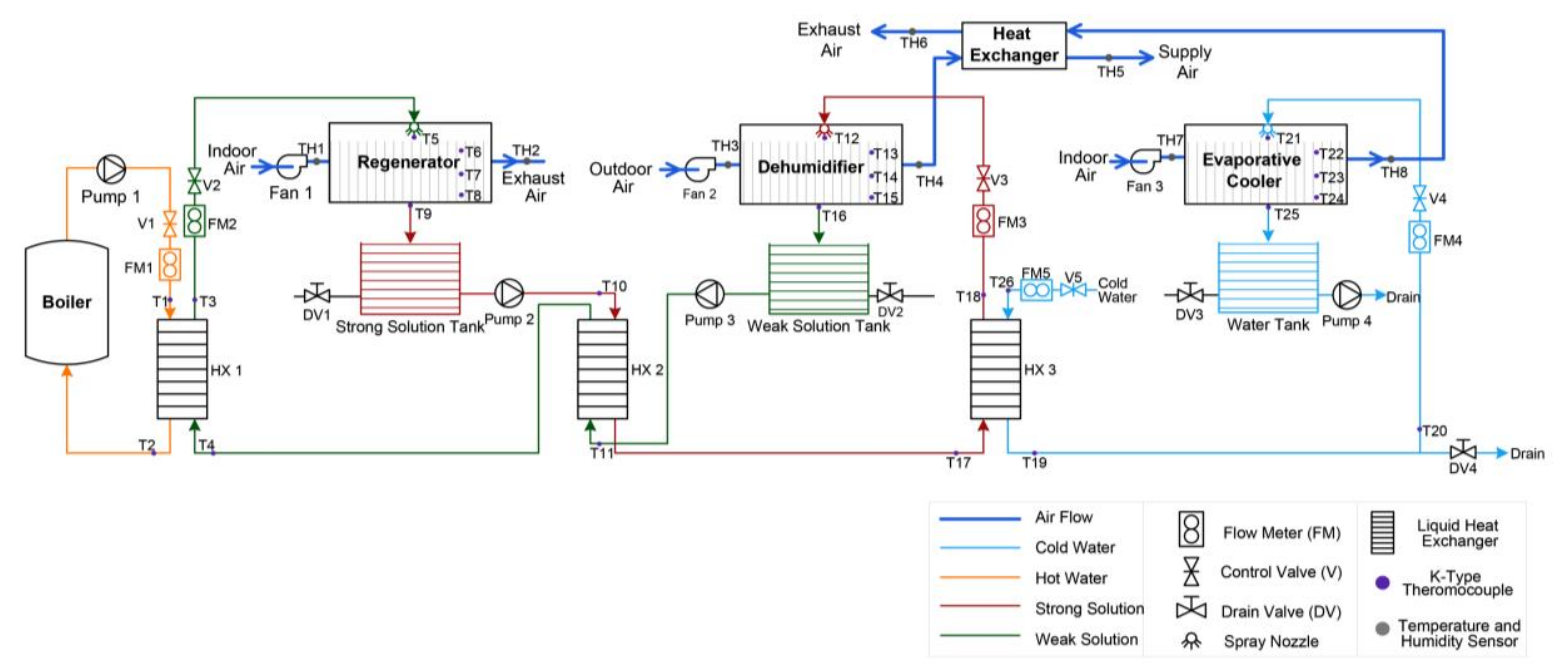

Fig. 2. Schematic graph of the MLDDC system

Aqueous $\mathrm{CaCl}_{2}$ is selected as the liquid desiccant solution. Photos of the experimental rig are shown in Fig. 3. An environmental chamber is employed to provide inlet air for the dehumidifier unit, which is capable to simulate the hot and humid climate condition. On the other hand, an air conditioner is used to supply air for the regenerator and evaporative cooler. With consideration of the surrounding effect, components such as air ducting, pipe work and heat exchangers are well insulated. 

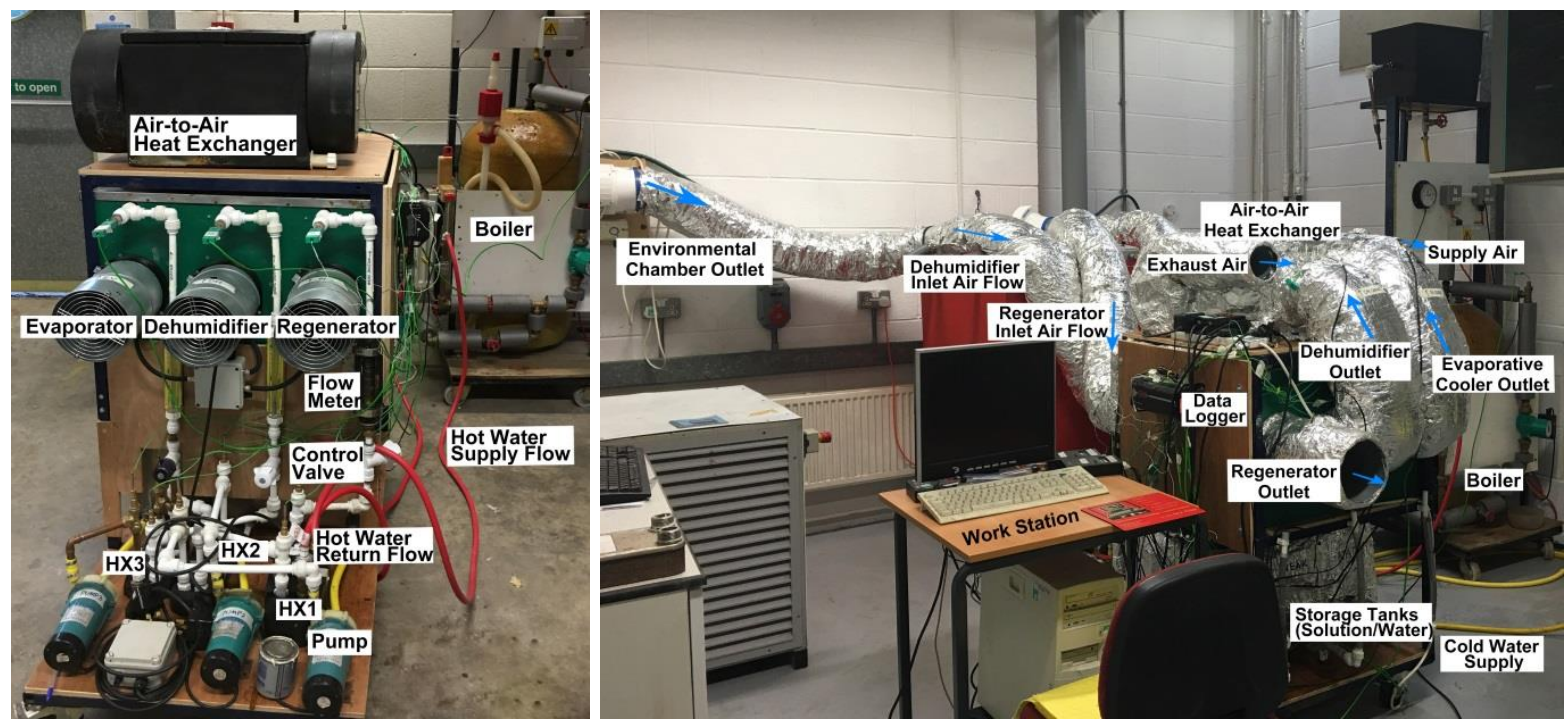

Fig. 3. Photos of the MLDDC system test rig

\subsection{Membrane-based unit}

Both the dehumidifier and regenerator are membrane-based units with specifications listed in

Table 1. The evaporative cooler has the same dimensions as the membrane-based unit, whereas its air channels are formed only by fibre sheets, which provide wet surfaces for water evaporation.

Table 1. Membrane-based unit specifications

\begin{tabular}{|l|l|l|}
\hline \multirow{2}{*}{ Unit dimension } & Length & $410 \mathrm{~mm}$ \\
\cline { 2 - 3 } & Width & $230 \mathrm{~mm}$ \\
\cline { 2 - 3 } & Height & $210 \mathrm{~mm}$ \\
\hline Membrane thickness & $0.11 \mathrm{~mm}$ \\
\hline Air channel barrier thickness & $0.13 \mathrm{~mm}$ \\
\hline \multirow{2}{*}{ Solution channel } & Quantity & 21 \\
\cline { 2 - 3 } & Width & $4.30 \mathrm{~mm}$ \\
\hline \multirow{2}{*}{ Air channel } & Quantity & 21 \\
\cline { 2 - 3 } & Width & $7.73 \mathrm{~mm}$ \\
\hline
\end{tabular}

The membrane-based unit has a series of separate channels in the cross-flow manner for the airstream and desiccant solution, as depicted in Fig. 4. The semi-permeable micro-porous hydrophobic membranes allow heat and moisture transfers between the airstream and desiccant solution while the liquid desiccant cannot permeate. Each solution channel is formed by two flat membrane sheets. During operation, the desiccant solution passes through the permeable 
barrier on the top and then flows downwards in the solution channels. Simultaneously, the gap between two solution channels allows the airstream to pass through for dehumidification or regeneration, where fibre materials are added only as supporting barriers.

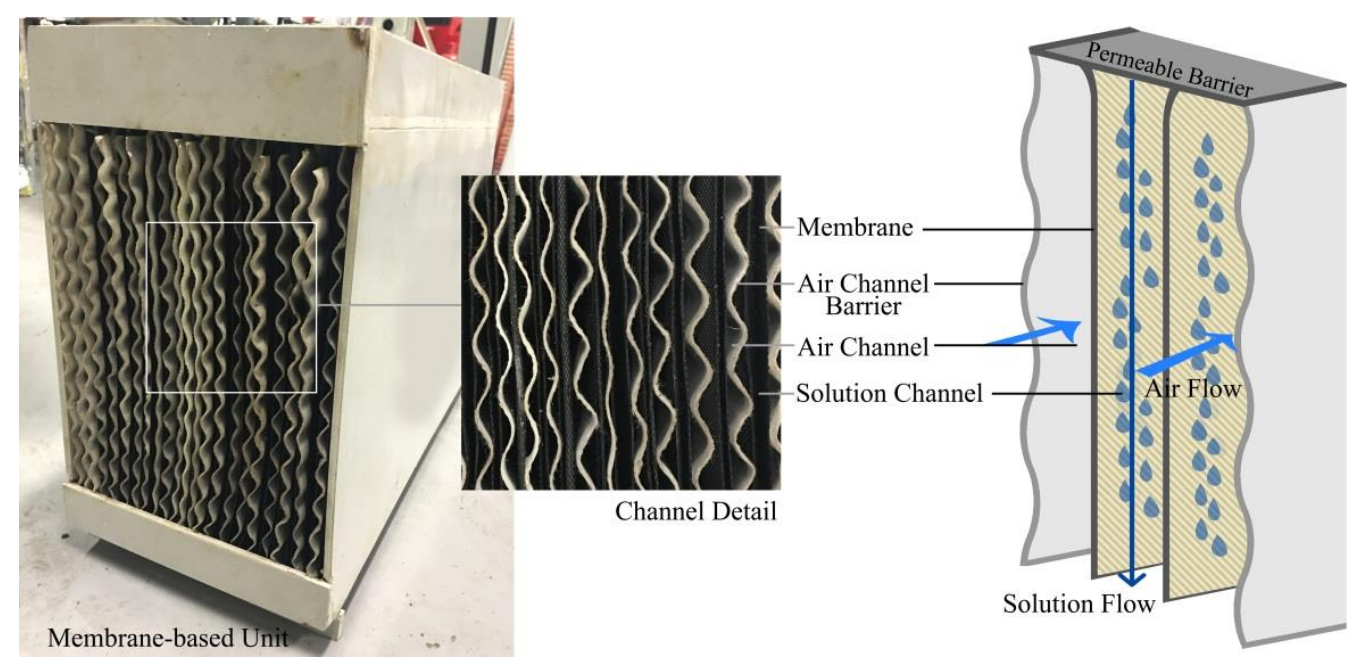

Fig. 4. Illustration of the membrane-based unit

\subsection{Measurement method}

The main measurement devices with their associated accuracies are presented in Table 2. A Testo anemometer is used to measure air velocity. Air temperatures and relative humidity at inlets and outlets of the dehumidifier, regenerator, evaporative cooler and air-to-air heat exchanger are obtained by Sensirion humidity sensors. K-type thermocouples are instrumented to measure the desiccant solution and water temperatures, and a data acquisition system is employed to record the data during operation.

Table 2. Measurement devices with associated accuracies

\begin{tabular}{|l|l|l|l|}
\hline Instrument & Parameter & Measurement Range & Accuracy \\
\hline Testo thermo-anemometer & Air velocity & $0-10 \mathrm{~m} / \mathrm{s}$ & $\pm 5 \%$ \\
\hline \multirow{2}{*}{ Sensirion humidity sensor } & Air temperature & $-40-+125^{\circ} \mathrm{C}$ & $\pm 0.3 \%$ \\
\cline { 2 - 4 } & Air relative humidity & $0-100 \%$ & $\pm 2 \%$ \\
\hline K-type thermocouple & Liquid temperature & $0-1100^{\circ} \mathrm{C}$ & $\pm 0.75 \%$ \\
\hline Data logger DT500 & Data Acquisition & $\pm 0.15 \%$ \\
\hline Brannan hydrometer 200 Series & Solution density & $1.0-1.6 \mathrm{~g} / \mathrm{m}^{3}$ & $\pm 2 \%$ \\
\hline Parker Easiflow meter & Liquid flow rate & $1-15 \mathrm{~L} / \mathrm{min}$ & $\pm 5 \%$ \\
\hline Parker liquid flow indicator & Liquid flow rate & $4-22 \mathrm{~L} / \mathrm{min}$ & $\pm 2 \%$ \\
\hline
\end{tabular}


The solution concentration ratio $\left(C_{\text {sol }}\right)$ is a function of the solution density and temperature, which is expressed as [38]:

$\rho_{\mathrm{sol}}\left(C_{\mathrm{sol}}, T_{\mathrm{sol}}\right)=\rho_{\mathrm{w}}\left(T_{\mathrm{sol}}\right) \cdot\left[1+0.836014 \cdot\left(\frac{C_{\mathrm{sol}}}{1-C_{\mathrm{sol}}}\right)-0.4363\left(\frac{C_{\mathrm{sol}}}{1-C_{\mathrm{sol}}}\right)^{2}+0.105642\left(\frac{C_{\mathrm{sol}}}{1-C_{\mathrm{sol}}}\right)^{3}\right]$

where, $T_{\text {sol }}$ and $\rho_{\text {sol }}$ are solution temperature in ${ }^{\circ} \mathrm{C}$ and density in $\mathrm{kg} / \mathrm{m}^{3}$ respectively. The solution density is measured by a Brannan hydrometer. $\rho_{\mathrm{w}}$ is saturated water density at $T_{\text {sol }}$, in $\mathrm{kg} / \mathrm{m}^{3}$.

Desiccant solution and water volumetric flow rates are measured by Parker liquid flow meters, which are calibrated with water at $20^{\circ} \mathrm{C}$. To equate the volumetric flow rate readings from the installed flow meters to the actual solution flow rates in the dehumidifier and regenerator, a correction correlation is used [39]:

$$
v_{\text {sol }}=v_{\mathrm{w}} \sqrt{\frac{\left(m_{\text {float }}-V_{\text {float }} \rho_{\text {sol }}\right) \rho_{\mathrm{w}}}{\left(m_{\text {float }}-V_{\text {float }} \rho_{\mathrm{w}}\right) \rho_{\text {sol }}}}
$$

where, $v_{\text {sol }}$ and $v_{\mathrm{w}}$ are volumetric flow rates of the desiccant solution and water respectively, in $\mathrm{L} / \mathrm{min} . m_{\text {float }}$ and $V_{\text {float }}$ are flow meter float weight in $\mathrm{kg}$ and volume in $\mathrm{m}^{3}$ respectively.

Once the desired inlet conditions for the three units are achieved, the entire system runs continuously until the steady state is reached and then the measured data is collected with a computer.

\subsection{Uncertainty analysis}

The uncertainty of each measurement instrument is listed in Table 2. Analysis is carried out to correlate the uncertainty of a calculated variable. The uncertainty $U_{\mathrm{Y}}$ of a variable Y can be derived from the function of uncertainty $U_{X_{\mathrm{i}}}$ of each measured variable $\mathrm{X}_{\mathrm{i}}$ [40]. 


$$
U_{\mathrm{Y}}=\sqrt{\sum_{i=1}^{N}\left(\frac{\partial Y}{\partial X_{i}}\right)^{2} \cdot U_{\mathrm{X}_{\mathrm{i}}}{ }^{2}}
$$

Error bars associated with the respective uncertainties are provided in the result analysis section.

\section{Performance Evaluation Metrics}

In terms of the dehumidification performance, it is evaluated by the moisture removal rate

$\left(\dot{M}_{\mathrm{r}}\right)$, and dehumidification effectiveness $\left(\varepsilon_{\mathrm{DH}}\right)$ which is defined as the ratio of the actual change in moisture content to the maximum moisture transfer.

$$
\begin{gathered}
\dot{M}_{\mathrm{r}}=\dot{m}_{\text {air_DH }} \cdot\left(\omega_{\text {in_DH }}-\omega_{\text {out_DH }}\right) \\
\varepsilon_{\mathrm{DH}}=\frac{\omega_{\text {in_DH }}-\omega_{\text {out_DH }}}{\omega_{\text {in_DH }}-\omega_{\text {eq_DH }}}
\end{gathered}
$$

where, $\dot{m}_{\text {air_DH }}$ is mass flow rate of the airstream passing through the dehumidifier in $\mathrm{kg} / \mathrm{s}$, $\omega_{\text {in_DH }}$ and $\omega_{\text {out_DH }}$ represent air humidity ratios at the dehumidifier inlet and outlet respectively, in $\mathrm{kg} / \mathrm{kg}_{\text {dryair, }}$, which are calculated based on the measured air temperature and relative humidity [41]. $\omega_{\text {eq_DH }}$ is equilibrium humidity ratio of the desiccant solution at the inlet condition, in $\mathrm{kg} / \mathrm{kg}_{\text {dryair. }}$ Referred to the empirical correlation derived in [42], a psychrometric chart illustrating the correlation of $\mathrm{CaCl}_{2}$ solution equilibrium humidity ratio with concentration ratio and temperature is presented in Fig. 5. 


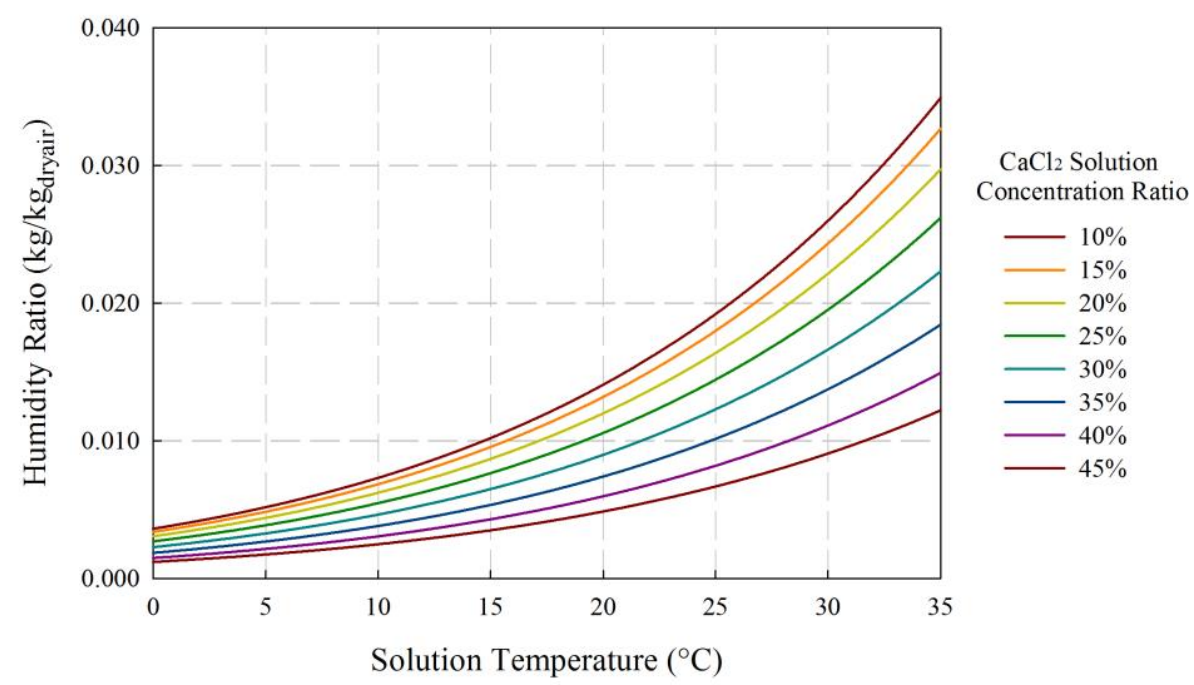

Fig. 5. $\mathrm{CaCl}_{2}$ solution equilibrium humidity ratio with concentration ratio and temperature

The regeneration performance is assessed by the moisture addition rate $\left(\dot{M}_{\mathrm{a}}\right)$.

$$
\dot{M}_{\mathrm{a}}=\dot{m}_{\text {air_RE }} \cdot\left(\omega_{\text {out_RE }}-\omega_{\text {in_RE }}\right)
$$

where, $\dot{m}_{\text {air_RE }}$ is air mass flow rate through the regenerator in $\mathrm{kg} / \mathrm{s} . \omega_{\text {in_RE }}$ and $\omega_{\text {out_RE }}$ are air humidity ratios at the regenerator inlet and outlet respectively, in $\mathrm{kg} / \mathrm{kg}_{\text {dryair }}$.

In addition, the evaporative cooling effectiveness $\left(\varepsilon_{\mathrm{EV}}\right)$ is defined to evaluate the evaporative cooler performance.

$$
\varepsilon_{\mathrm{EV}}=\frac{T_{\text {in_EV }}-T_{\text {out_EV }}}{T_{\text {in_EV }}-T_{\text {wb_in_EV }}}
$$

where, $T_{\text {in_Ev }}$ and $T_{\text {out_Ev }}$ are air dry bulb temperatures at the evaporative cooler inlet and outlet respectively, in ${ }^{\circ} \mathrm{C} . T_{\text {wb_in_Ev }}$ is air wet bulb temperature at the evaporative cooler inlet, in ${ }^{\circ} \mathrm{C}$. Based on the airstream enthalpy difference between the inlet and outlet, the dehumidifier cooling output $\left(\dot{Q}_{\mathrm{DH} \_ \text {cooling }}\right)$ and system total cooling output $\left(\dot{Q}_{\text {cooling }}\right)$ are determined:

$$
\begin{gathered}
\dot{Q}_{\text {DH_cooling }}=\dot{m}_{\text {air_DH }}\left(h_{\text {in_DH }}-h_{\text {out_DH }}\right) \\
\dot{Q}_{\text {cooling }}=\dot{m}_{\text {air_DH }}\left(h_{\text {in_DH }}-h_{\text {supply }}\right)
\end{gathered}
$$


where, $h_{\text {in_DH }}$ and $h_{\text {out_DH }}$ are specific enthalpies of the airstream entering and leaving the dehumidifier respectively, in $\mathrm{J} / \mathrm{kg}$, and $h_{\text {supply }}$ is supply air enthalpy, in $\mathrm{J} / \mathrm{kg}$.

The MLDDC system overall coefficient of performance (COP) is defined as:

$$
\mathrm{COP}=\frac{\dot{Q}_{\text {cooling }}}{\dot{Q}_{\mathrm{RE}}}
$$

where $\dot{Q}_{\mathrm{RE}}$ is regenerator thermal input power in $\mathrm{W}$ and can be expressed as

$$
\dot{Q}_{\mathrm{RE}}=\dot{m}_{\mathrm{w} \_\mathrm{RE}} \cdot c_{\mathrm{p} \_ \text {w_RE }}\left(T_{\mathrm{w} \_\mathrm{f}}-T_{\mathrm{w} \_\mathrm{r}}\right)
$$

where, $\dot{m}_{\mathrm{w}_{-} \mathrm{RE}}$ and $c_{\mathrm{p} \__{-} \_\mathrm{RE}}$ are hot water mass flow rate in $\mathrm{kg} / \mathrm{s}$ and specific heat capacity in $\mathrm{J} / \mathrm{kg} \cdot \mathrm{K} . T_{\mathrm{w}_{-} \mathrm{f}}$ and $T_{\mathrm{w}_{-} \mathrm{r}}$ are hot water supply and return temperatures in the heating circuit respectively, in ${ }^{\circ} \mathrm{C}$.

\section{Results and Discussion}

The influences of operating variables on the dehumidification, regeneration, evaporative cooling and overall system performances are analysed respectively in this section. As defined in Section 3, the main performance parameters include the dehumidification moisture removal rate, effectiveness and cooling output, the regeneration moisture addition rate and thermal input power, the evaporative cooling effectiveness, the system total cooling output and COP. Based on the $\mathrm{CaCl}_{2}$ solution operative concentration level for dehumidification, its concentration ratio ranging from $30 \%$ to $42 \%$ is selected in this study. Solution flow rates in the dehumidifier and regenerator units remain the same at $1 \mathrm{~L} / \mathrm{min}$ throughout investigations, which are able to provide sufficient wetting surfaces in the membrane units for continuous operation. Hot and cold water are supplied at flow rates of $2 \mathrm{~L} / \mathrm{min}$ and $12 \mathrm{~L} / \mathrm{min}$ respectively. 


\subsection{Dehumidification performance}

\subsubsection{Influence of inlet air condition}

Experimental tests are firstly conducted to evaluate the dehumidification performance under various inlet air conditions at a $\mathrm{CaCl}_{2}$ solution concentration ratio of $39 \%$. The investigated inlet air conditions provided by the environmental chamber are shown in Fig. 6. To simulate different weather conditions in the hot and humid region, the dehumidifier inlet air is set in the temperature range of $28.0^{\circ} \mathrm{C}$ to $40.0^{\circ} \mathrm{C}$ and relative humidity ranges from $65 \%$ to $95 \%$. The absolute humidity ratio varies from $16.39 \mathrm{~g} / \mathrm{kg}_{\text {dryair }}$ to $36.48 \mathrm{~g} / \mathrm{kg}_{\text {dryair }}$ accordingly.

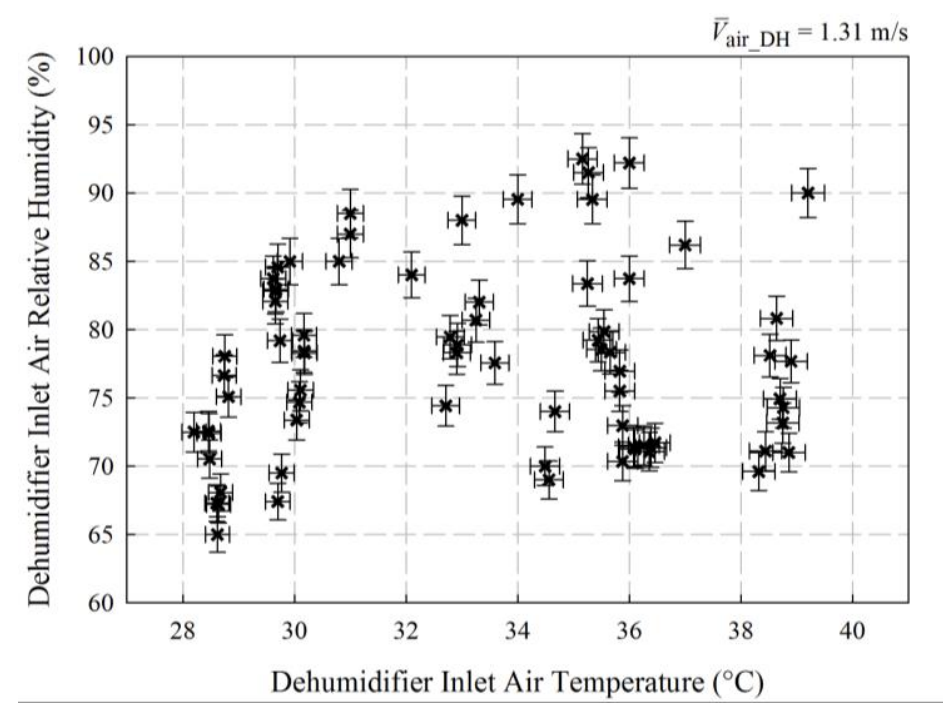

Fig. 6. Investigated dehumidifier inlet air condition range

As shown in Fig. 7, the dehumidification performance improves with inlet air temperature and relative humidity. The higher the air temperature and relative humidity, the higher the vapour pressure, and more mass transfer occurs owing to the greater vapour pressure difference between the airstream and desiccant solution. Consequently, the evident increases in the dehumidification moisture removal rate, effectiveness and cooling output are observed. For example, when the dehumidifier inlet air temperature is maintained at $36.0^{\circ} \mathrm{C}$, the moisture removal rate increases from $0.15 \mathrm{~g} / \mathrm{s}$ to $0.25 \mathrm{~g} / \mathrm{s}$ as the air relative humidity rises from $71 \%$ to $92 \%$, and correspondingly the dehumidification effectiveness increases from 0.50 to 0.68 and 
the dehumidifier cooling output increases from $332.6 \mathrm{~W}$ to $642.3 \mathrm{~W}$. This is because of the increase in the inlet air humidity ratio with relative humidity at a constant temperature, which causes more mass transfer in the dehumidification process. Similarly, the dehumidification performance improves with inlet air temperature under a constant relative humidity condition. For instance, at an inlet air relative humidity level of $75 \%$, the moisture removal rate increases from $0.06 \mathrm{~g} / \mathrm{s}$ at air temperature of $29.0^{\circ} \mathrm{C}$ to $0.22 \mathrm{~g} / \mathrm{s}$ at air temperature of $39.0^{\circ} \mathrm{C}$ and simultaneously, the dehumidification effectiveness improves by 0.34 and the cooling output increases by $451.6 \mathrm{~W}$. This is due to the fact that the inlet air humidity ratio increases with air temperature while the relative humidity remains constant. Thus more heat and mass transfer takes place and the associated cooling load increases. The effects of inlet air condition on the dehumidification performance in this study are consistent with those in [24, 33, 36, 43, 44]. For instance, the dehumidifier performance of a MLDDC system with a potassium formate desiccant solution is experimentally investigated under various inlet air conditions in [33]. According to their experimental data, the moisture removal rate increases by approximately $35.69 \%$ at inlet air relative humidity of $60 \%$ as the inlet air temperature rises from $30^{\circ} \mathrm{C}$ to $35^{\circ} \mathrm{C}$. Over the investigated inlet air relative humidity range of $50 \%$ to $70 \%$, the dehumidification effectiveness improves from 0.32 to 0.47 and the dehumidifier cooling output increases by $303 \mathrm{~W}$ at inlet air temperature of $35^{\circ} \mathrm{C}$. These results indicate that the outdoor weather condition significantly affects the dehumidification performance and by comparison, the inlet air temperature has a more notable impact on the dehumidification performance. 


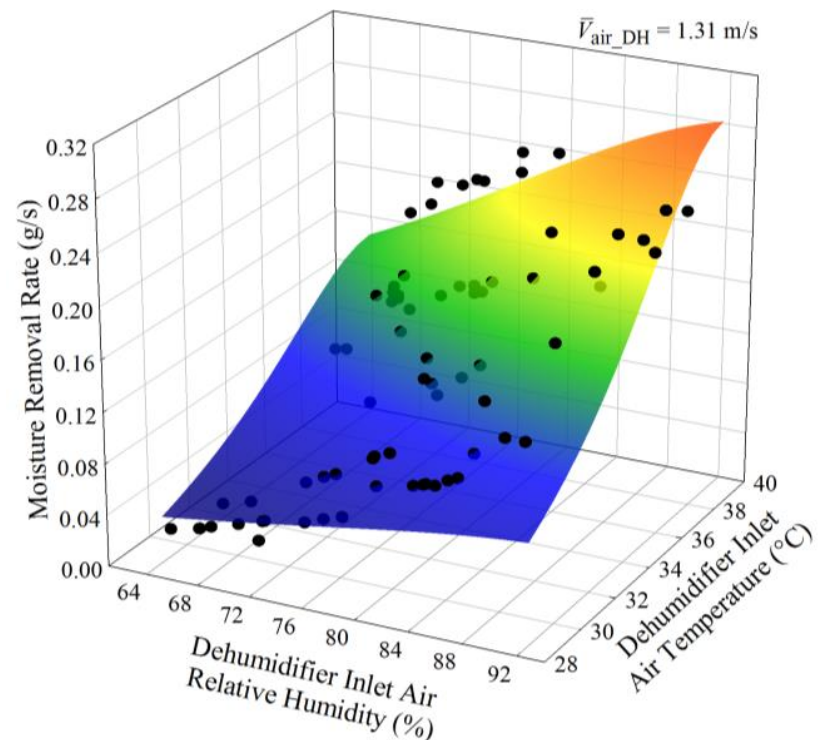

(a)

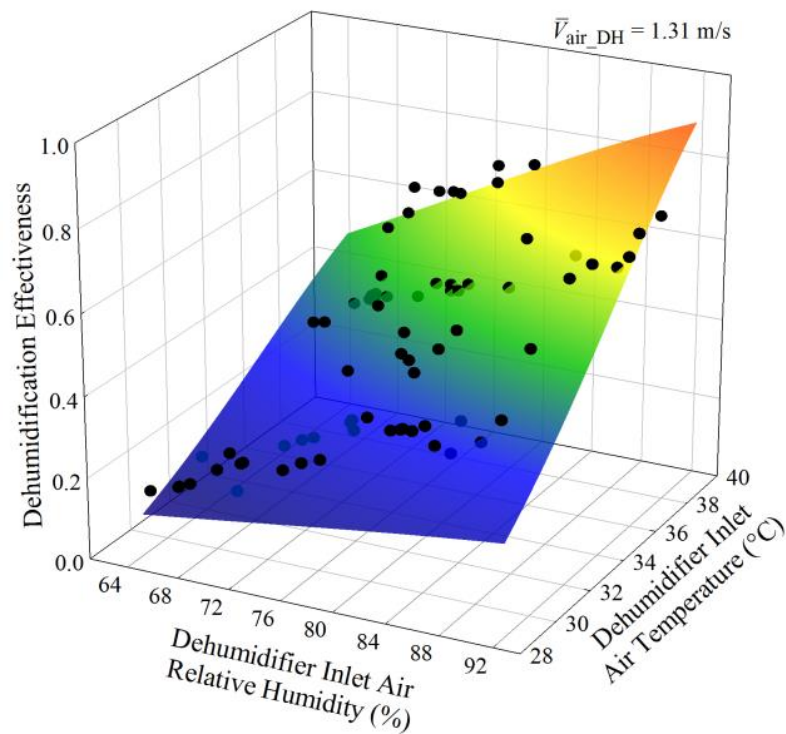

(b) 


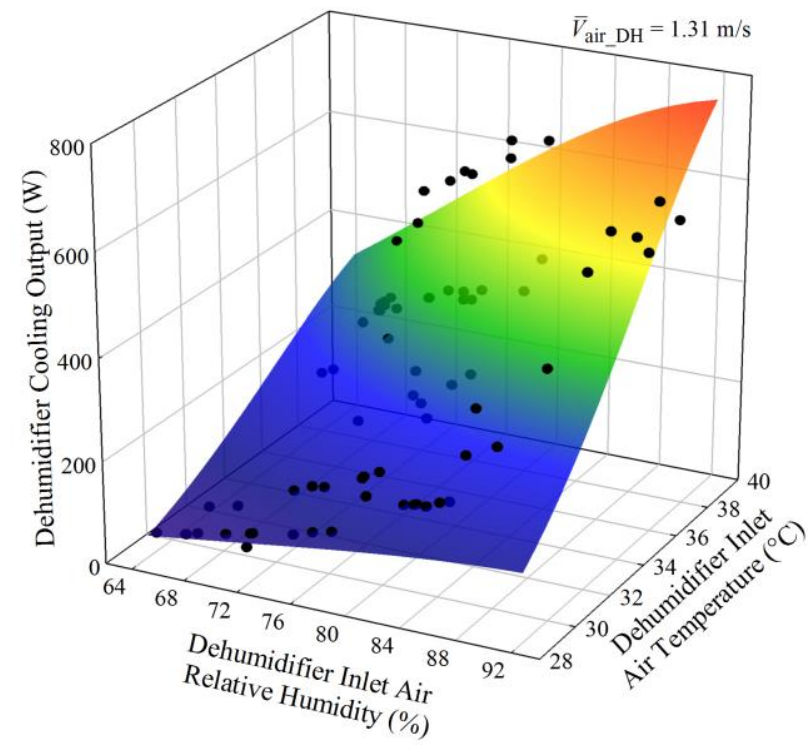

(c)

Fig. 7. Influences of inlet air condition on dehumidifier (a) moisture removal rate, (b) dehumidification effectiveness and (c) cooling output

\subsubsection{Influence of air flow rate}

In order to assess the impact of air flow rate on the dehumidification performance, tests are carried out for the solution concentration ratio in the range of $30 \%$ to $42 \%$ with the inlet air temperature of $34.0^{\circ} \mathrm{C}$ and relative humidity of $72 \%$. The influence of air flow rate is presented in Fig.8, it can be noted that the variation in the dehumidification performance is not very significant. At a solution concentration ratio of $42 \%$, the moisture content change in the dehumidification process is $8.62 \mathrm{~g} / \mathrm{kg}_{\text {dryair }}$ at air flow rate of $34.17 \mathrm{~m}^{3} / \mathrm{h}$, and it reduces to $7.47 \mathrm{~g} / \mathrm{kg}_{\text {dryair }}$ at air flow rate of $45.88 \mathrm{~m}^{3} / \mathrm{h}$. This is due to the fact that the dehumidification capability decreases with air flow rate. However, the moisture removal rate is a function of air flow rate and moisture content change, which increases with air flow rate as displayed in Fig. 8(a). For instance, the moisture removal rate increases by $16.72 \%$ over the investigated air flow rate range at a concentration ratio of $36 \%$. As indicated in Fig. 8(b), the dehumidification effectiveness decreases with air flow rate at a given solution concentration ratio. The influences of air flow rate on the moisture removal rate and dehumidification effectiveness in this study 
are in good agreement with those in [45]. With $\mathrm{LiCl}$ as the liquid desiccant for an LDDC system, the dehumidifier moisture removal rate increases from $0.17 \mathrm{~g} / \mathrm{s}$ to $0.21 \mathrm{~g} / \mathrm{s}$ as the inlet air flow rate rises from $70 \mathrm{~kg} / \mathrm{h}$ to $115 \mathrm{~kg} / \mathrm{h}$, while the dehumidification effectiveness reduces from 0.67 to 0.51 correspondingly [45]. On the other hand, a high flow rate causes a large volume of air being conditioned in the dehumidifier, thus the dehumidifier cooling output increases accordingly as shown in Fig. 8(c).

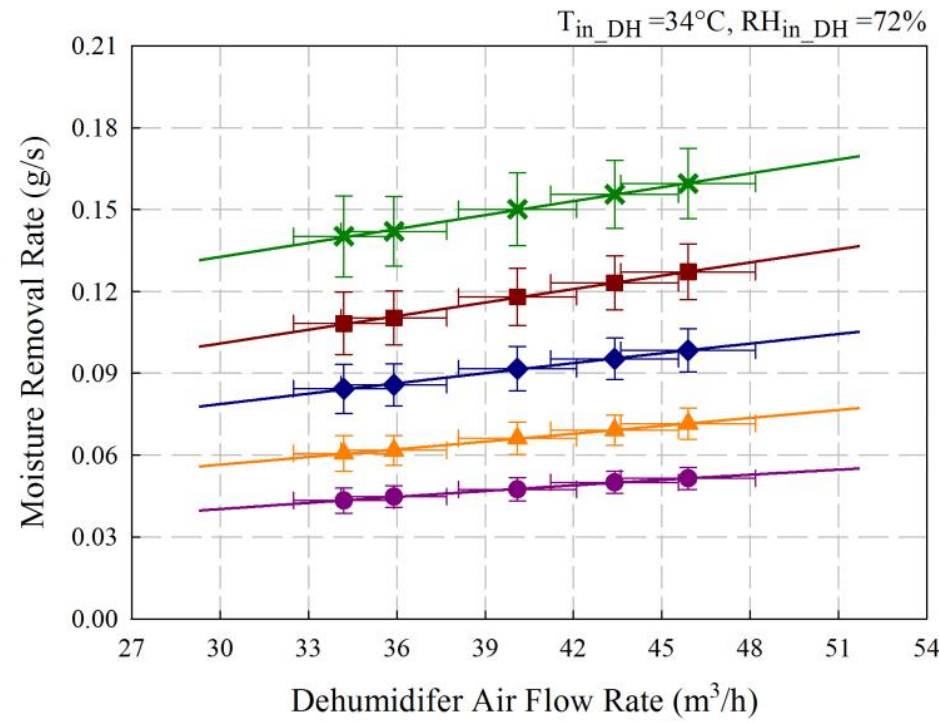

$\mathrm{CaCl}_{2}$ Solution

Concentration Ratio

$\times \quad 42 \%$

- $39 \%$

$-36 \%$

- $33 \%$

- $30 \%$

(a)

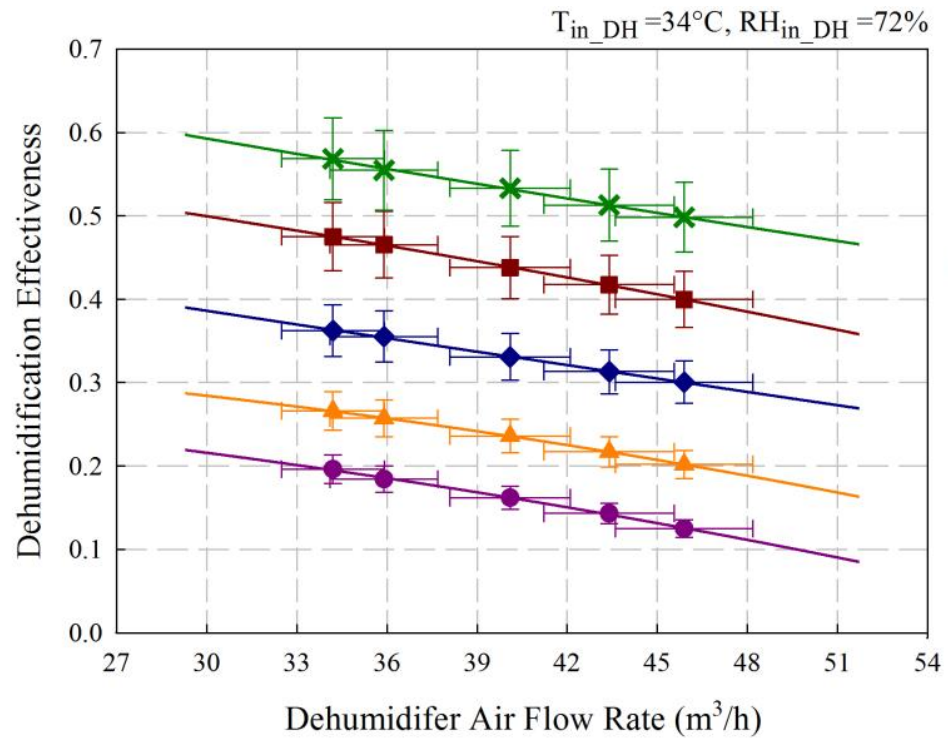

$\mathrm{CaCl}_{2}$ Solution

Concentration Ratio

$\times \quad 42 \%$

- $39 \%$

- $36 \%$

- $33 \%$

- $30 \%$

(b) 


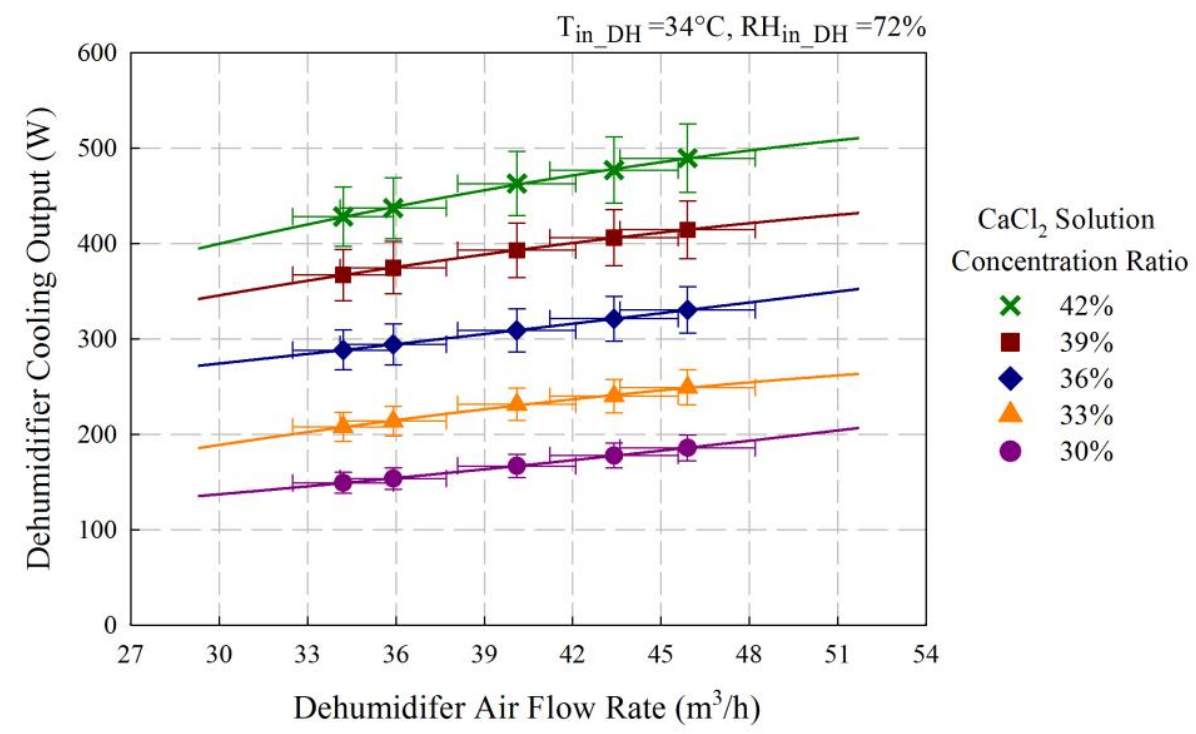

(c)

Fig. 8. Influences of air flow rate on dehumidifier (a) moisture removal rate, (b) dehumidification effectiveness and (c) cooling output

\subsubsection{Influence of cold water temperature}

The effect of cold water temperature on the dehumidification performance is then investigated as cold water is utilized to cool the regenerated solution prior to flowing into the dehumidifier. The dehumidifier inlet air condition is maintained constant, while cold water is supplied in the temperature range of $10.0^{\circ} \mathrm{C}$ to $20.0^{\circ} \mathrm{C}$. Temperature variations in the dehumidifier sprayed solution and outlet air with cold water temperature are shown in Fig. 9. It can be seen that the desiccant solution spray temperature rises in accordance with cold water temperature from $13.9^{\circ} \mathrm{C}$ to $24.2^{\circ} \mathrm{C}$ at a solution concentration ratio of $42 \%$, and the dehumidifier outlet air temperature increases from $29.5^{\circ} \mathrm{C}$ to $33.1^{\circ} \mathrm{C}$ accordingly. 


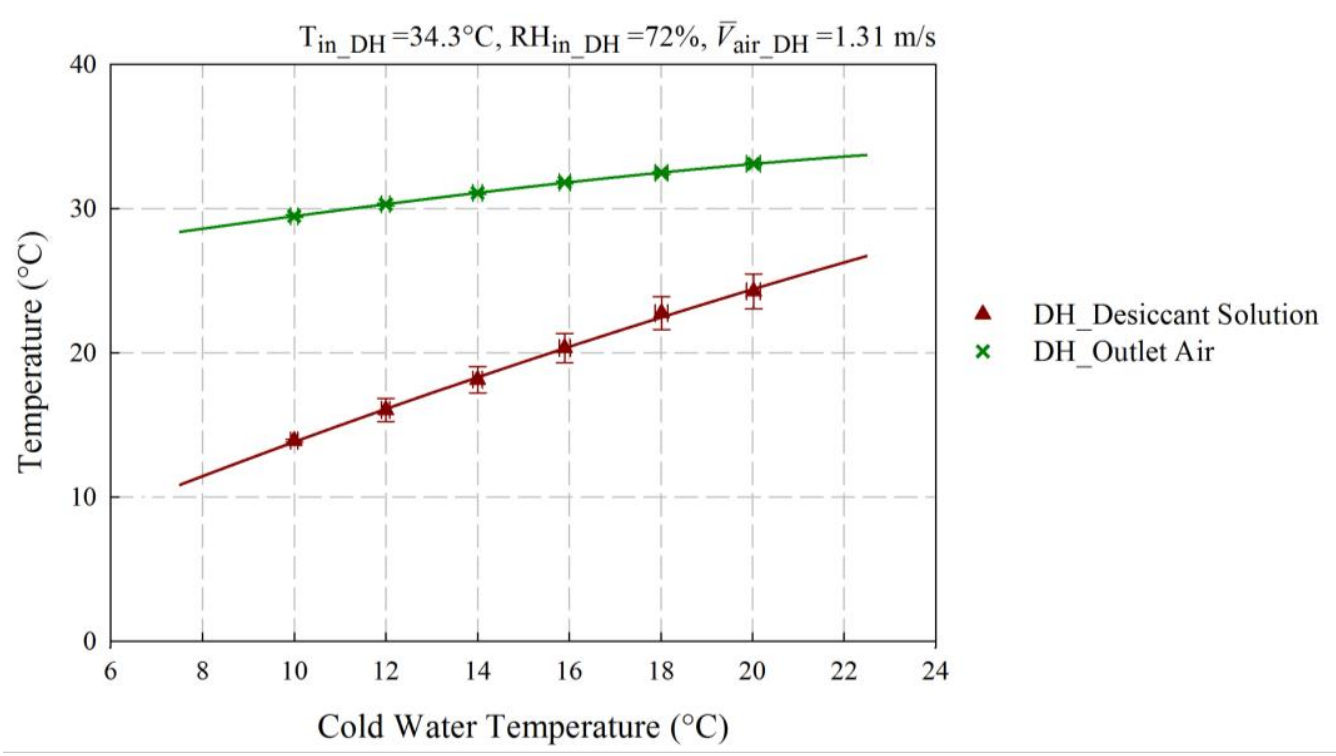

Fig. 9. Variations in dehumidifier solution spray temperature and outlet air temperature with cold water temperature

The increase in the desiccant solution spray temperature has a negative impact on the dehumidification performance as shown in Fig. 10. At a solution concentration ratio of $42 \%$, the moisture removal rate reduces by $32.04 \%$ as the cold water temperature increases by $10^{\circ} \mathrm{C}$, the dehumidification effectiveness decreases by $21.12 \%$ and the dehumidifier cooling output decreases by $28.23 \%$. This is because that a higher desiccant solution temperature causes higher vapour pressure on the solution side, so less mass transfer occurs in the dehumidification process with a smaller vapour pressure difference between the solution and airstream. The results imply that an enhancement in the dehumidification performance can be achieved by lowering the desiccant solution spray temperature in the dehumidifier, which is also stated in [44]. Based on their experimental results of a MLDDC system, the dehumidifier moisture removal rate decreases by $41.2 \%$ as the dehumidifier solution inlet temperature rises from $15^{\circ} \mathrm{C}$ to $25^{\circ} \mathrm{C}$ at a $\mathrm{LiCl}$ solution concentration ratio of $30 \%$. 


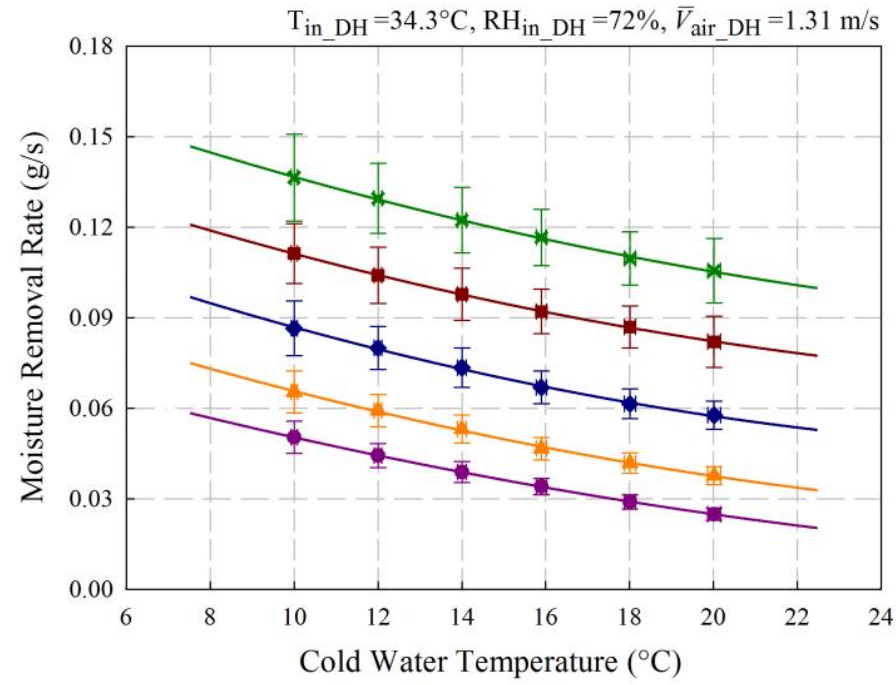

$\mathrm{CaCl}_{2}$ Solution

Concentration Ratio

$$
\begin{array}{r}
42 \% \\
\times \quad 39 \% \\
\hline \quad 36 \% \\
\hline \quad 33 \% \\
\hline
\end{array}
$$

(a)

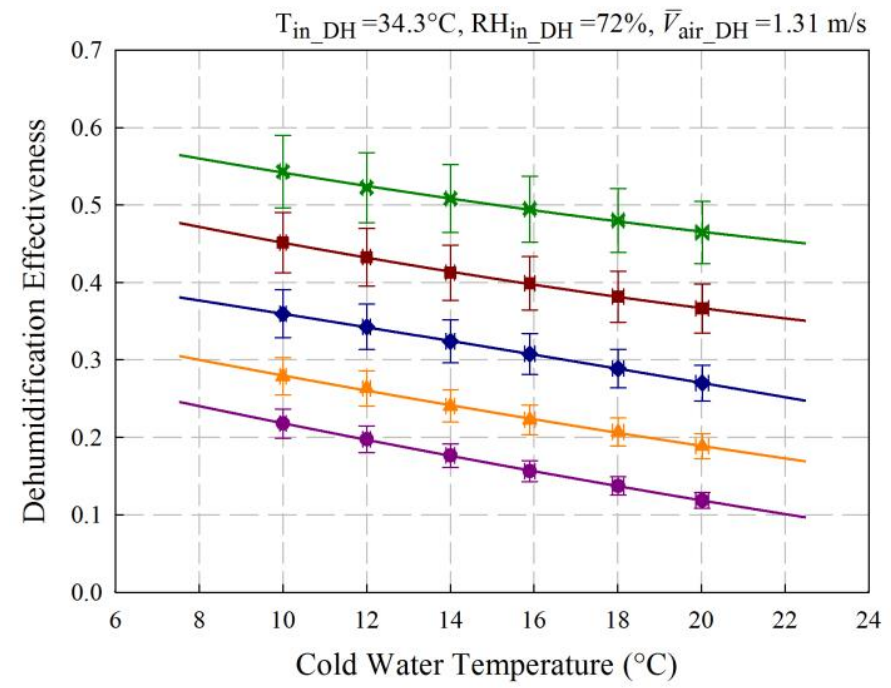

$\mathrm{CaCl}_{2}$ Solution Concentration Ratio

$\times \quad 42 \%$

- $39 \%$

- $36 \%$

- $33 \%$

- $30 \%$

(b)

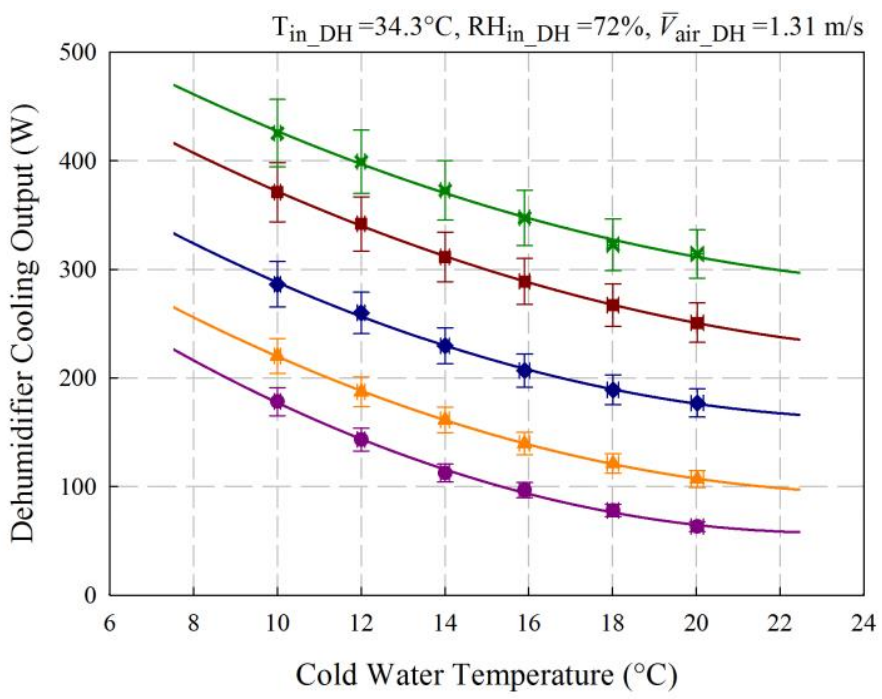

$\mathrm{CaCl}_{2}$ Solution

Concentration Ratio

$\times \quad 42 \%$

- $39 \%$

- $36 \%$

A $33 \%$

- $30 \%$

(c)

Fig. 10. Influences of cold water temperature on dehumidifier (a) moisture removal rate, (b) dehumidification effectiveness and (c) cooling output 


\subsubsection{Influence of solution concentration ratio}

It is noteworthy that the solution concentration ratio has a remarkable influence on the dehumidification performance, which has been confirmed by many researchers [45-48]. A higher solution concentration ratio contributes to better dehumidification performance as seen in Fig.8 and Fig.10. Under the investigated operating condition (i.e. the dehumidifier inlet air flow rate of $35.93 \mathrm{~m}^{3} / \mathrm{h}$ and cold water temperature of $10^{\circ} \mathrm{C}$ ), the moisture removal rate is only $0.05 \mathrm{~g} / \mathrm{s}$ at a solution concentration ratio of $30 \%$, while it increases to $0.14 \mathrm{~g} / \mathrm{s}$ at a concentration ratio of $42 \%$, simultaneously, the dehumidification effectiveness improves from 0.22 to 0.56 and the dehumidifier cooling output increases from $178.2 \mathrm{~W}$ to $425.4 \mathrm{~W}$. This is attributed to the larger vapour pressure difference between the airstream and desiccant solution at a higher concentration ratio, thus more moisture can be removed in the dehumidification process. A similar impact of $\mathrm{LiCl}$ solution concentration ratio on the dehumidification performance is presented in [45]. The dehumidifier moisture removal rate increases from $0.06 \mathrm{~g} / \mathrm{s}$ at a $\mathrm{LiCl}$ solution concentration ratio of $26 \%$ to $0.21 \mathrm{~g} / \mathrm{s}$ at a concentration ratio of $39 \%$ and the dehumidification effectiveness improves from 0.34 to 0.61 consequently.

\subsection{Regeneration performance}

\subsubsection{Influence of air flow rate}

Similarly, the effect of air flow rate on the regeneration performance is identified. The regenerator inlet air temperature and relative humidity are set at $26.0^{\circ} \mathrm{C}$ and $30 \%$ respectively, while its air flow rate rises from $43.82 \mathrm{~m}^{3} / \mathrm{h}$ to $148.44 \mathrm{~m}^{3} / \mathrm{h}$. The increase in the regenerator air flow rate leads to a reduction in the moisture absorption capability. Nevertheless, the regeneration performance, which is assessed by the moisture addition rate, improves with air flow rate as shown in Fig. 11. At a concentration ratio of $30 \%$, the moisture addition rate reaches $0.08 \mathrm{~g} / \mathrm{s}$ at air flow rate of $148.44 \mathrm{~m}^{3} / \mathrm{h}$, while only $0.01 \mathrm{~g} / \mathrm{s}$ is achieved at flow rate of 
$43.82 \mathrm{~m}^{3} / \mathrm{h}$. The same variation trend of the regenerator performance with air flow rate is indicated in [48], the moisture addition rate improves by $44.45 \%$ as the regenerator air flow rate increases from $0.12 \mathrm{~kg} / \mathrm{s}$ to $0.24 \mathrm{~kg} / \mathrm{s}$.

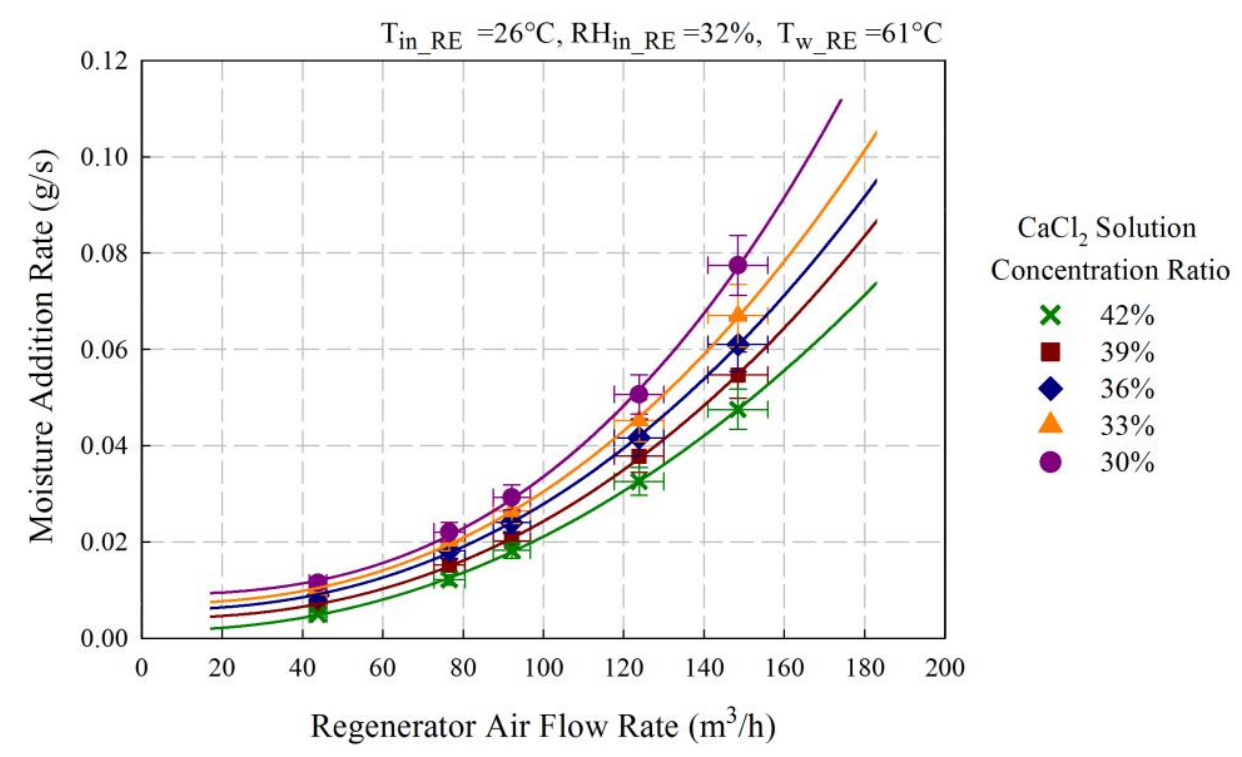

Fig. 11. Influence of air flow rate on regenerator moisture addition rate

The variation of the regenerator thermal input power with air flow rate at a solution concentration ratio of $42 \%$ is demonstrated in Fig. 12. Over the investigated air flow rate range, the hot water temperature difference in the heating circuit varies from $4.1{ }^{\circ} \mathrm{C}$ to $5.2^{\circ} \mathrm{C}$, as a result, the regenerator thermal input power is in the range of $568.9 \mathrm{~W}$ to $728.6 \mathrm{~W}$. The higher the air flow rate, the more the thermal input power for heating the dilute solution. This finding is consistent with the statement in [47] that the regenerator air flow rate is a critical parameter influencing the regeneration performance. Therefore, the required thermal input power should be taken into account to determine the regenerator air flow rate. 


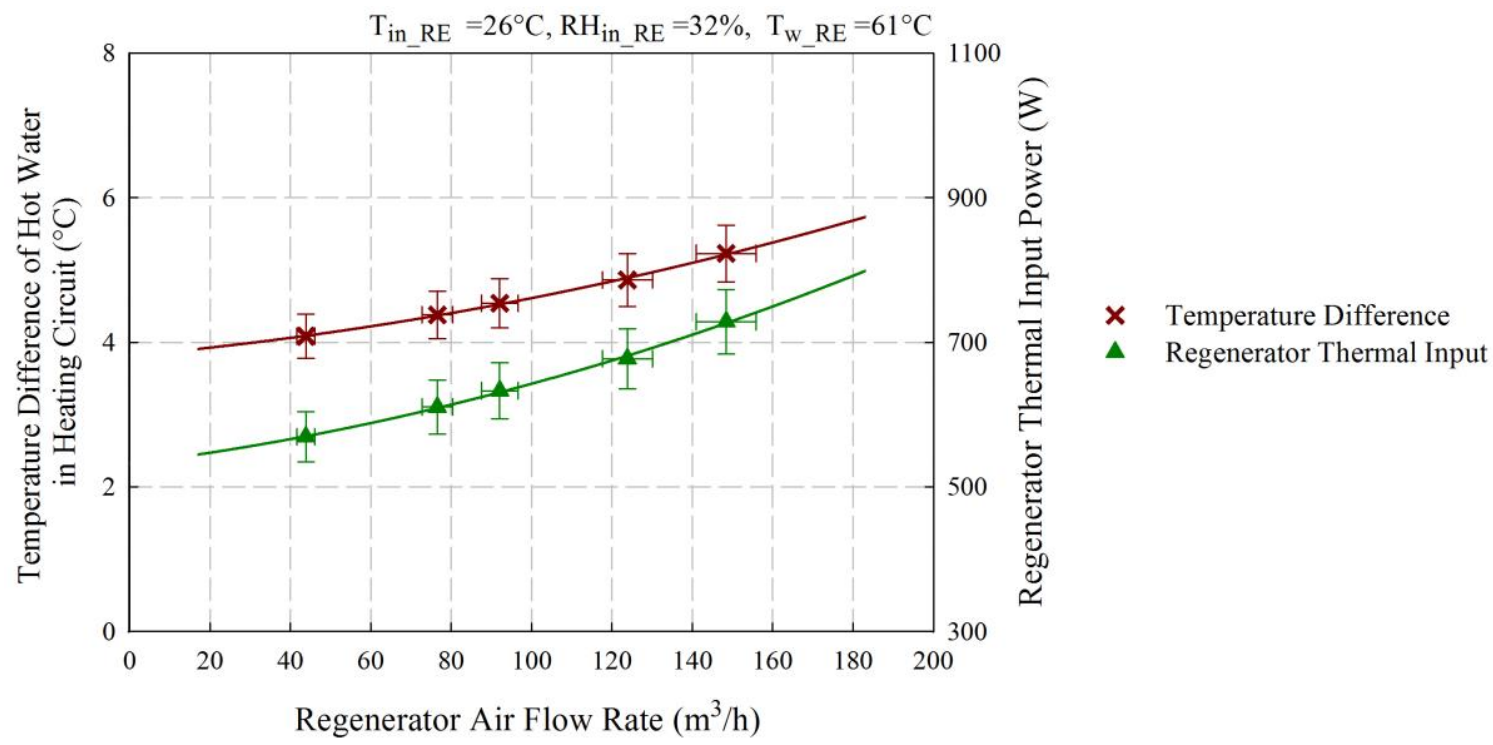

Fig. 12. Influence of air flow rate on regenerator thermal input power

\subsubsection{Influence of regeneration hot water temperature}

In this study, hot water from a boiler is utilized for regeneration purpose. In order to clarify the influence of the regeneration temperature on the regeneration performance, the hot water temperature is set in the range of $55.0^{\circ} \mathrm{C}$ to $80.0^{\circ} \mathrm{C}$ while the regenerator inlet air is maintained at a temperature of $26.0^{\circ} \mathrm{C}$ and relative humidity of $33 \%$. The impact of hot water temperature on the regeneration moisture addition rate is indicated in Fig. 13. It can be observed that the regeneration performance greatly improves with hot water temperature. For instance, the moisture addition rate increases by $72.32 \%$ as the hot water temperature rises from $55.0^{\circ} \mathrm{C}$ to $80.0^{\circ} \mathrm{C}$ at a solution concentration ratio of $42 \%$, while it doubles at a concentration ratio of $30 \%$. A similar effect of hot water on the regeneration performance is found in an LDDC system using $\mathrm{LiBr}$ aqueous solution [48], an approximately 30\% increase in the moisture addition rate is obtained as hot water temperature rises from $31^{\circ} \mathrm{C}$ to $42^{\circ} \mathrm{C}$. A higher hot water temperature causes higher vapour pressure of the desiccant solution in the regenerator; hence more mass transfer from the solution to airstream occurs because of a greater vapour pressure difference. 


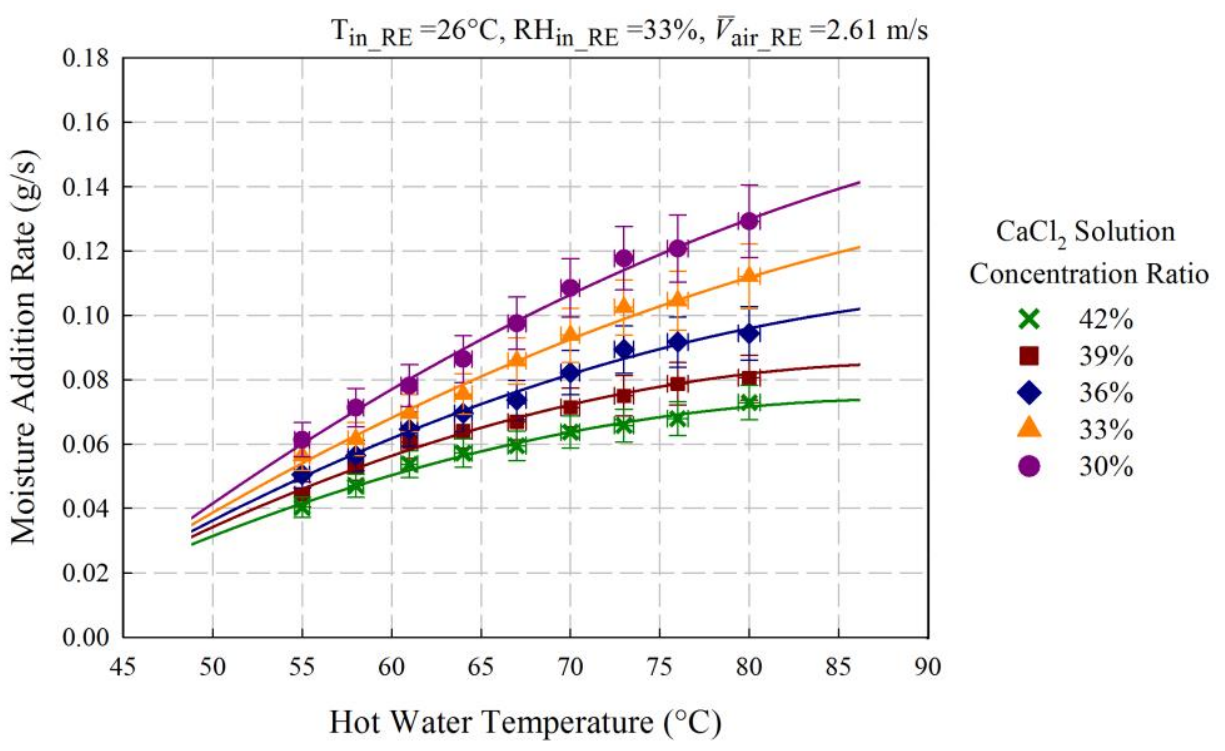

Fig. 13. Influence of hot water temperature on regenerator moisture addition rate

On the other hand, a considerable increase in the regenerator thermal input power with hot water temperature is observed, as illustrated in Fig. 14. At a solution concentration ratio of $42 \%$, the thermal input power doubles as the hot water temperature rises from $55.0^{\circ} \mathrm{C}$ to $80.0^{\circ} \mathrm{C}$. The higher the hot water temperature, the better the regeneration performance, but simultaneously more thermal input power is required.

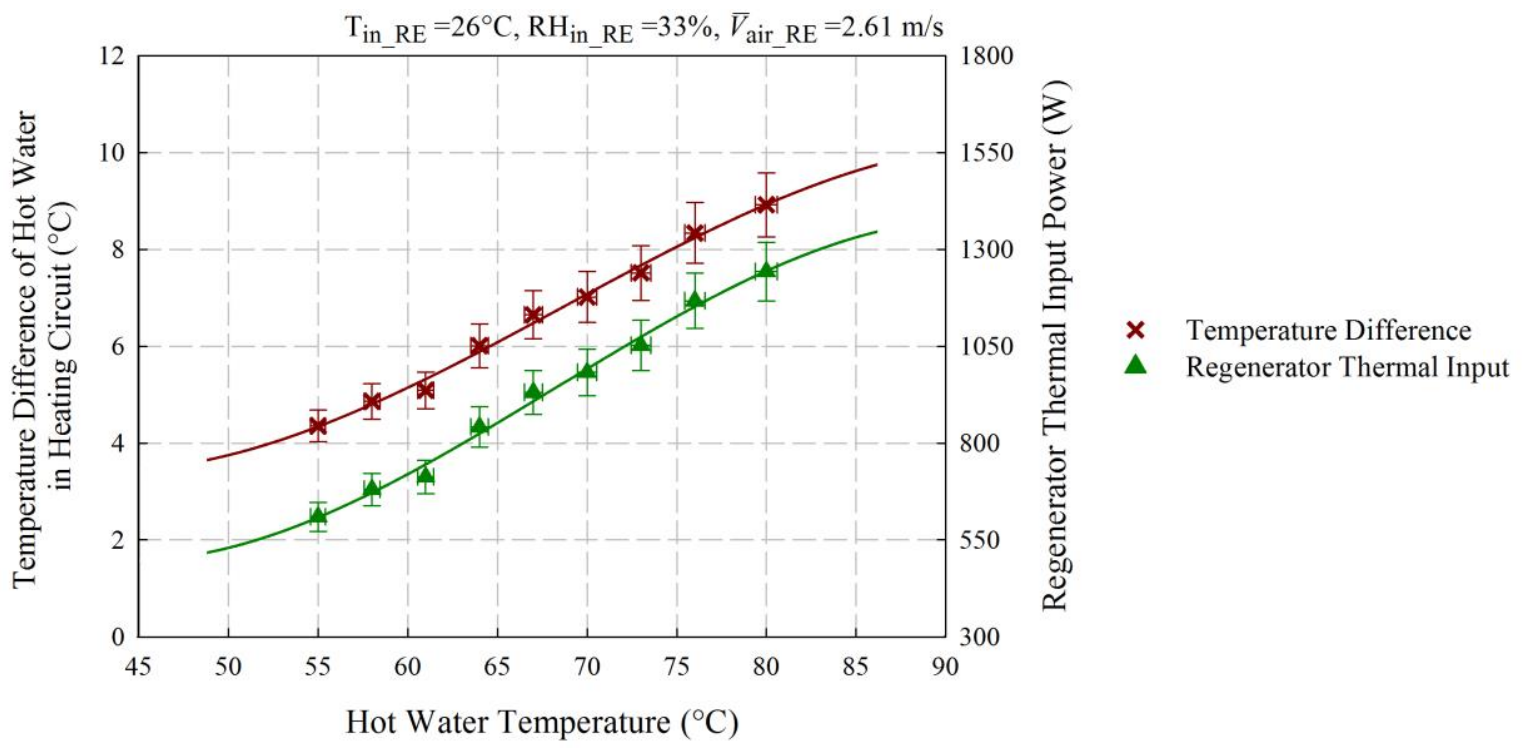

Fig. 14. Influence of hot water temperature on regenerator thermal input power 


\subsubsection{Influence of solution concentration ratio}

It can be noted that a better regeneration performance is achieved at a lower solution concentration ratio as shown in Fig. 11 and Fig. 13. For example, at air flow rate of $148.44 \mathrm{~m}^{3} / \mathrm{h}$, the moisture addition rate increases by $63.83 \%$ as the solution concentration ratio decreases from $42 \%$ to $30 \%$. In the regeneration process, less mass transfer takes place at a higher concentration ratio due to the lower vapour pressure. Similarly, the effect of $\mathrm{LiCl}$ solution concentration ratio on the regeneration performance is demonstrated in [49]. The regenerator moisture addition rate reduces by $10.14 \%$ as the concentration ratio of $\mathrm{LiCl}$ solution increases from $32 \%$ to $35 \%$. On the other hand, a more significant moisture addition rate variation with hot water temperature is observed at a lower concentration ratio as presented in Fig. 13. It is also worth noting that the increase rate in the moisture addition rate with hot water temperature slows down gradually. For example, at a concentration ratio of $42 \%$, only a slight change in the moisture addition rate (i.e. $0.01 \mathrm{~g} / \mathrm{s}$ ) is observed with a hot water temperature range of $65.0^{\circ} \mathrm{C}$ to $80.0^{\circ} \mathrm{C}$. Thus, an appropriate regeneration temperature range should be determined for the adequate regeneration performance based on the operative solution concentration ratio in order to avoid the excessive thermal input power and improve the overall system energy performance.

\subsection{Evaporative cooling performance}

Tests are carried out to identify the effect of cold water temperature on the evaporative cooling performance. Variations of the cooler outlet air temperature and evaporative cooling effectiveness are shown in Fig. 15. Under the constant inlet air condition, the evaporative cooler outlet air temperature increases from $19.4^{\circ} \mathrm{C}$ to $23.8^{\circ} \mathrm{C}$ and the evaporative effectiveness decreases from 0.72 to 0.37 as the cold water temperature rises from $10.0^{\circ} \mathrm{C}$ to $20.0^{\circ} \mathrm{C}$. In this system, the cold water supplied at a lower temperature not only evidently leads to the better 
evaporative cooling performance [23] but also contributes to an improvement in the dehumidification performance as discussed in Section 4.1.3.

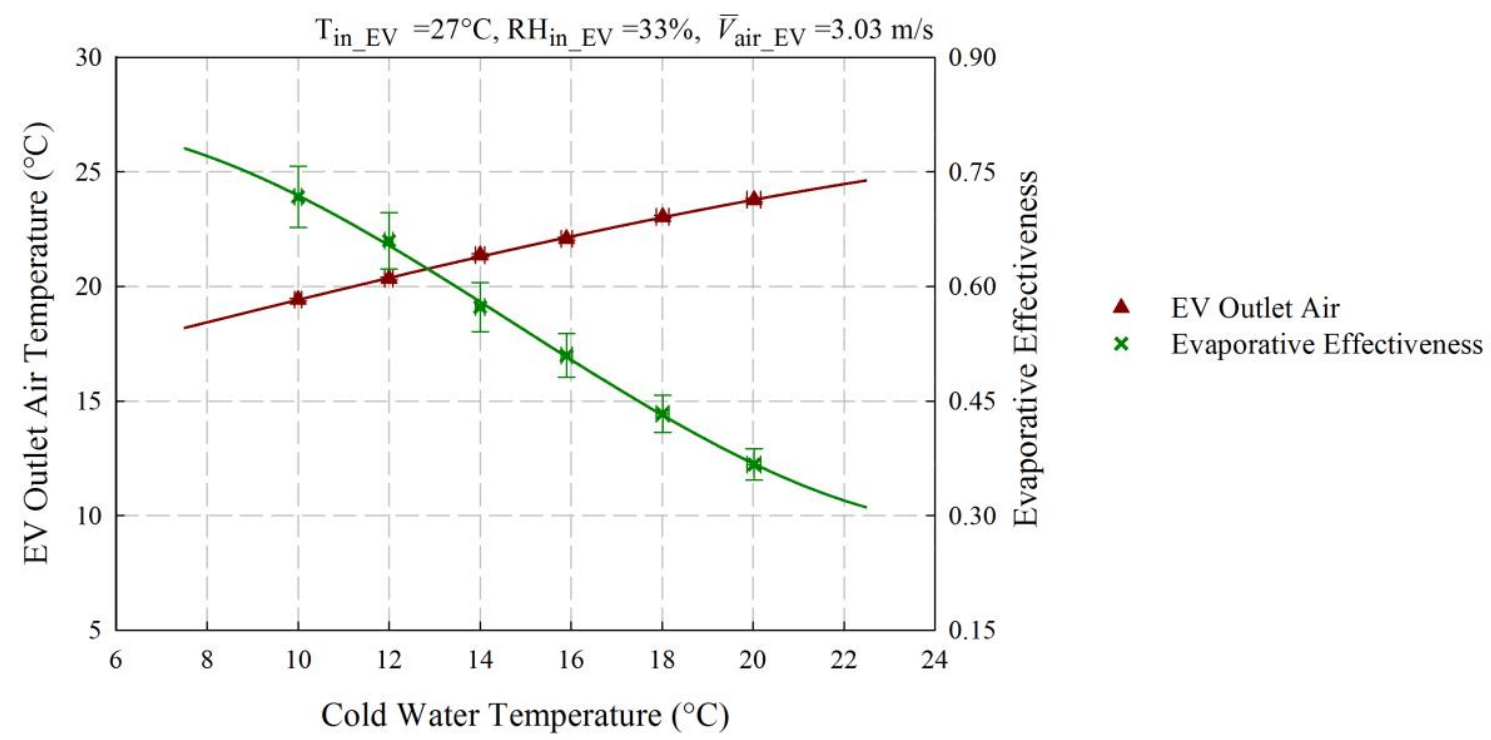

Fig. 15. Variations in evaporative cooler outlet air temperature and its effectiveness with cold water temperature

\subsection{System performance}

With respect to the system steady operation at a given solution concentration ratio, the performance balance between the dehumidifier and regenerator is of great importance as desiccant mass imbalance problems may occur over time, such as the dilution of the solution with insufficient regeneration and a more concentrated solution with excessive regeneration [33]. As mentioned previously, both the dehumidification and regeneration performances vary remarkably with the desiccant solution concentration ratio. Referred to Sections 4.1 and 4.2, the dehumidification moisture removal rate and regeneration moisture addition rate at different solution concentration ratios are presented in Fig. 16, which are obtained under the individual operating states. It is noteworthy that the entire system is capable to run steadily at a solution concentration ratio of $36 \%$ under the stated operating condition, at which the dehumidifier moisture removal rate and regenerator moisture addition rate match each other. 
For the system operating steadily at the other concentration ratios, measures should be taken to balance the dehumidification and regeneration performances. For the concentration ratio below $36 \%$, the dehumidification performance should be improved to match with that of the regeneration. As discussed in Section 4.1, increasing the dehumidifier air flow rate is one of the approaches to enhance the moisture removal rate. For example, the dehumidifier air flow rate of $110 \mathrm{~m}^{3} / \mathrm{h}$ is needed to ensure its moisture removal rate to match with the regenerator moisture addition rate at a solution concentration ratio of $30 \%$, while the dehumidifier air flow rate is required at $55 \mathrm{~m}^{3} / \mathrm{h}$ for the concentration ratio of $33 \%$. On the other hand, for the solution concentration ratio over $36 \%$, the regenerator moisture addition rate should be increased to eliminate the imbalance issue. It is stated in Section 4.2 that the increases in the regenerator air flow rate and hot water temperature result in better regeneration performance. Based on the experimental analysis, the regenerator air flow rates should be kept at $200 \mathrm{~m}^{3} / \mathrm{h}$ and $240 \mathrm{~m}^{3} / \mathrm{h}$ for concentration ratios of $39 \%$ and $42 \%$ respectively. Moreover, an appropriate regeneration hot water temperature range should be selected to avoid the excessive thermal input power.

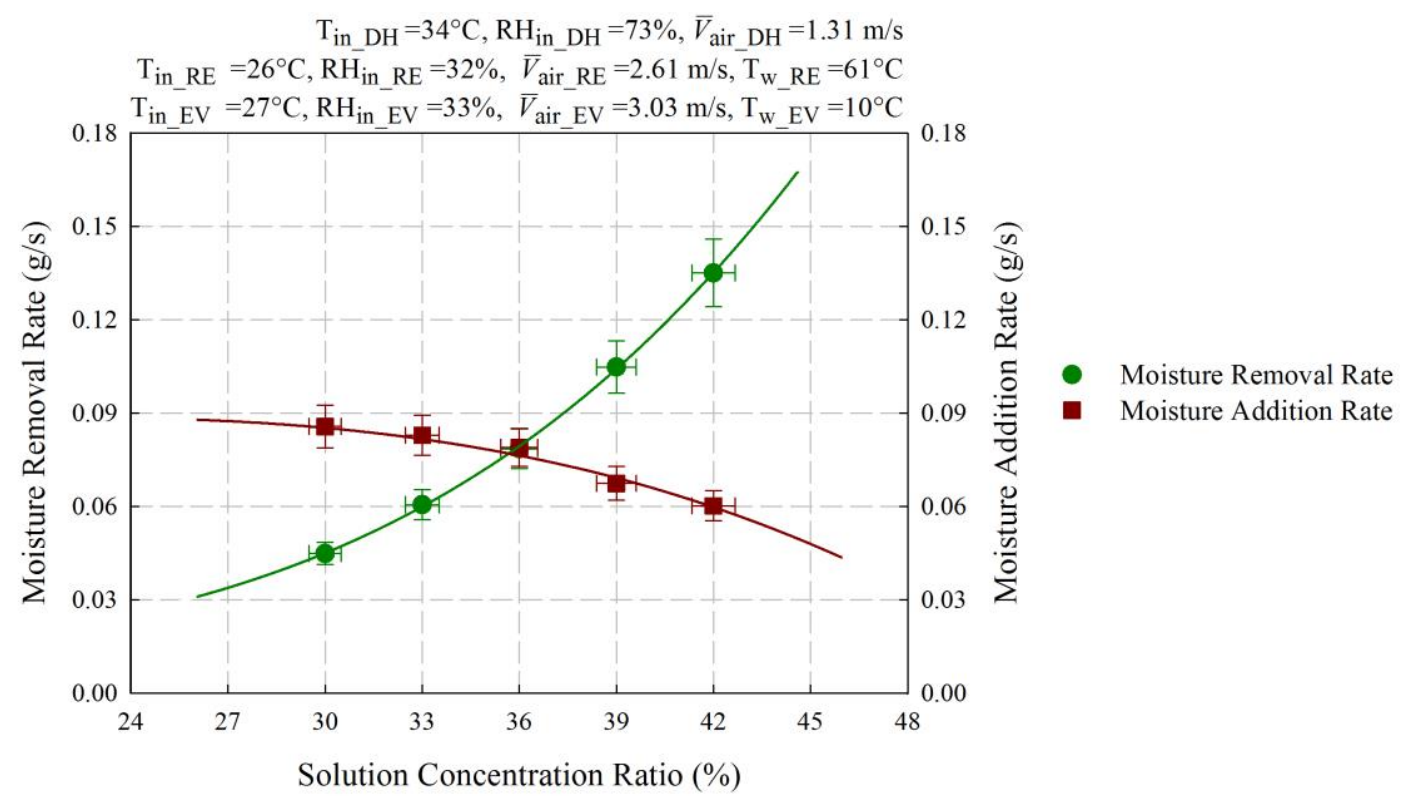

Fig. 16. Variations in system moisture removal and addition rates with solution concentration ratio 
The overall system performance is evaluated by the system COP. Referred to the previous analysis, it can be projected that a higher system COP is obtained at a lower solution concentration ratio, for example, the system COP reaches 0.74 at a concentration ratio of $30 \%$ while it is only 0.61 at a concentration ratio of $42 \%$. For the concentration ratio below $36 \%$, improving the dehumidification performance (i.e. increasing the dehumidifier air flow rate) contributes to more total cooling output, and thus a comparatively higher system COP is achieved. On the contrary, for the concentration ratio over $36 \%$, improving the regeneration performance (i.e. increasing the regenerator air flow rate or hot water temperature) requires much more thermal input power, so that the system COP is relatively lower. Alternatively, the regenerator could be designed with a large dimension as stated in [33], which provides a large contact area for more heat and mass transfer in the regeneration process. Furthermore, the crystallization problem may appear for a high concentrated solution, which causes the risks of fluid mal-distribution, channel blockage, high pumping pressure, and membrane fouling [48]. For example, at a solution concentration ratio of $42 \%, \mathrm{CaCl}_{2}$ solution begins crystalizing at a temperature of $16.0^{\circ} \mathrm{C}$.

\subsubsection{Influence of cold water temperature}

Under the stated operating condition, the effect of cold water temperature on the system performance is assessed at solution concentration ratio of $36 \%$. The evident declines in the system total cooling output and COP with cold water temperature are observed in Fig. 17. The system total cooling output reduces from $486.7 \mathrm{~W}$ at cold water temperature of $10.0^{\circ} \mathrm{C}$ to $339.6 \mathrm{~W}$ at cold water temperature of $20.0^{\circ} \mathrm{C}$, and the $\mathrm{COP}$ decreases from 0.70 to 0.59 accordingly. As mentioned in Section 4.1.3, the cold water temperature influences the desiccant solution spray temperature in the dehumidifier, the solution spray temperature increases from $13.9^{\circ} \mathrm{C}$ to $24.2^{\circ} \mathrm{C}$ as the cold water temperature rises from $10^{\circ} \mathrm{C}$ to $20^{\circ} \mathrm{C}$. A similar impact of the dehumidifier solution temperature is presented in [44], the system COP reduces from 0.75 
to 0.65 as the $\mathrm{LiCl}$ solution temperature increases from $15^{\circ} \mathrm{C}$ to $25^{\circ} \mathrm{C}$ at the dehumidifier inlet. The results imply that colder water is preferred for better dehumidification and system performances, which is also suggested by Gandhidasan [12]. In addition, varying cold water temperature could also be a solution to reach the desired supply air temperature. According to the experimental data, the supply air temperature rises from $20.4^{\circ} \mathrm{C}$ to $24.8^{\circ} \mathrm{C}$ as the cold water temperature rises from $10^{\circ} \mathrm{C}$ to $20^{\circ} \mathrm{C}$.

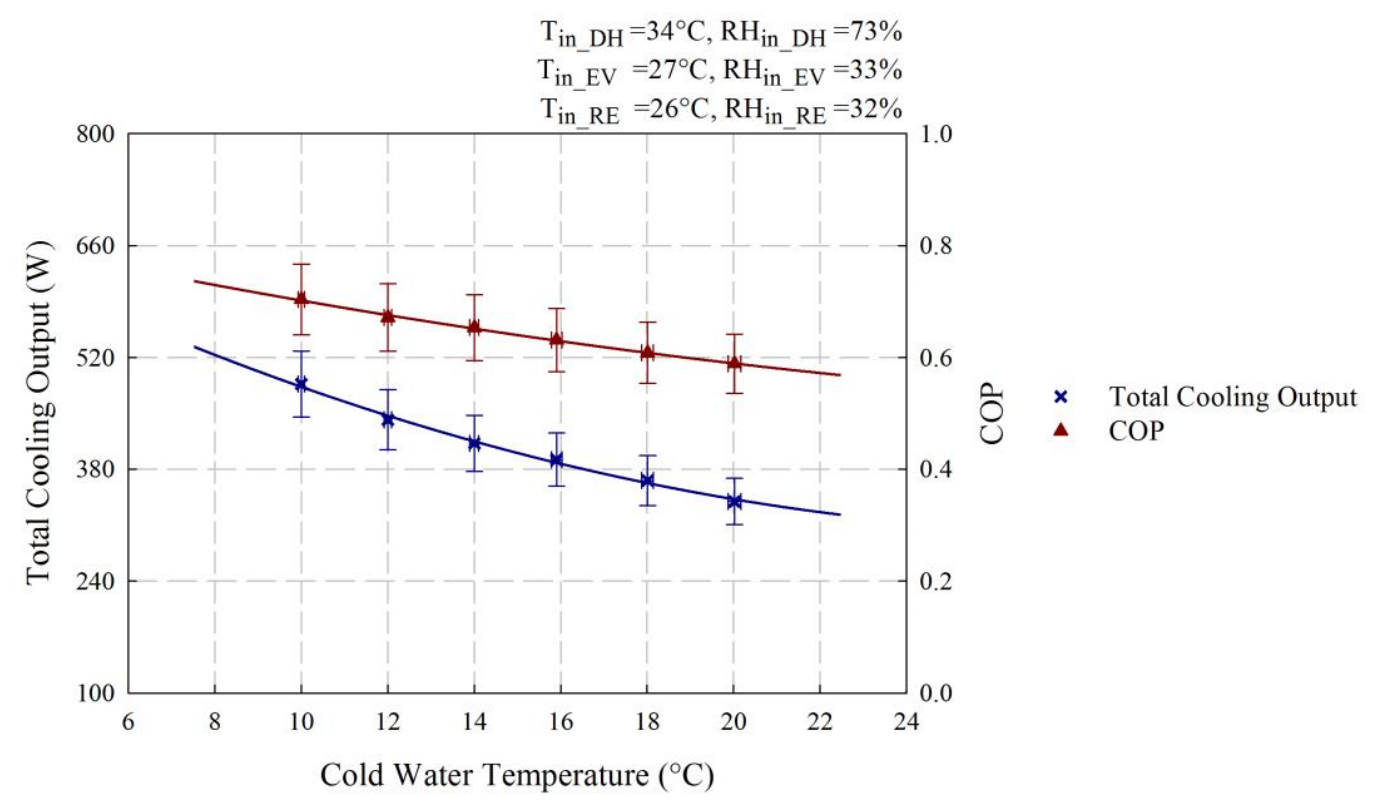

Fig. 17. Influences of cold water temperature on system cooling output and COP

\subsubsection{Influence of regeneration temperature}

The effect of hot water temperature on the system performance is indicated in Fig. 18. At a solution concentration ratio of $36 \%$, the regenerator thermal input power increases by $635.3 \mathrm{~W}$ while the system COP reduces by $21.33 \%$ as the hot temperature rises from $55.0^{\circ} \mathrm{C}$ to $80.0^{\circ} \mathrm{C}$. The desiccant solution temperature at the regenerator inlet varies in line with the hot water temperature. Similarly, an evident reduction in the system COP with the regenerator desiccant solution temperature is also noted in [44], the system COP decreases by approximately $17 \%$ when the $\mathrm{LiCl}$ solution temperature at the regenerator inlet rises from $40^{\circ} \mathrm{C}$ to $65^{\circ} \mathrm{C}$. The results reveal that more thermal input power is required to attain a higher regeneration temperature and thereby a lower system COP is obtained. 


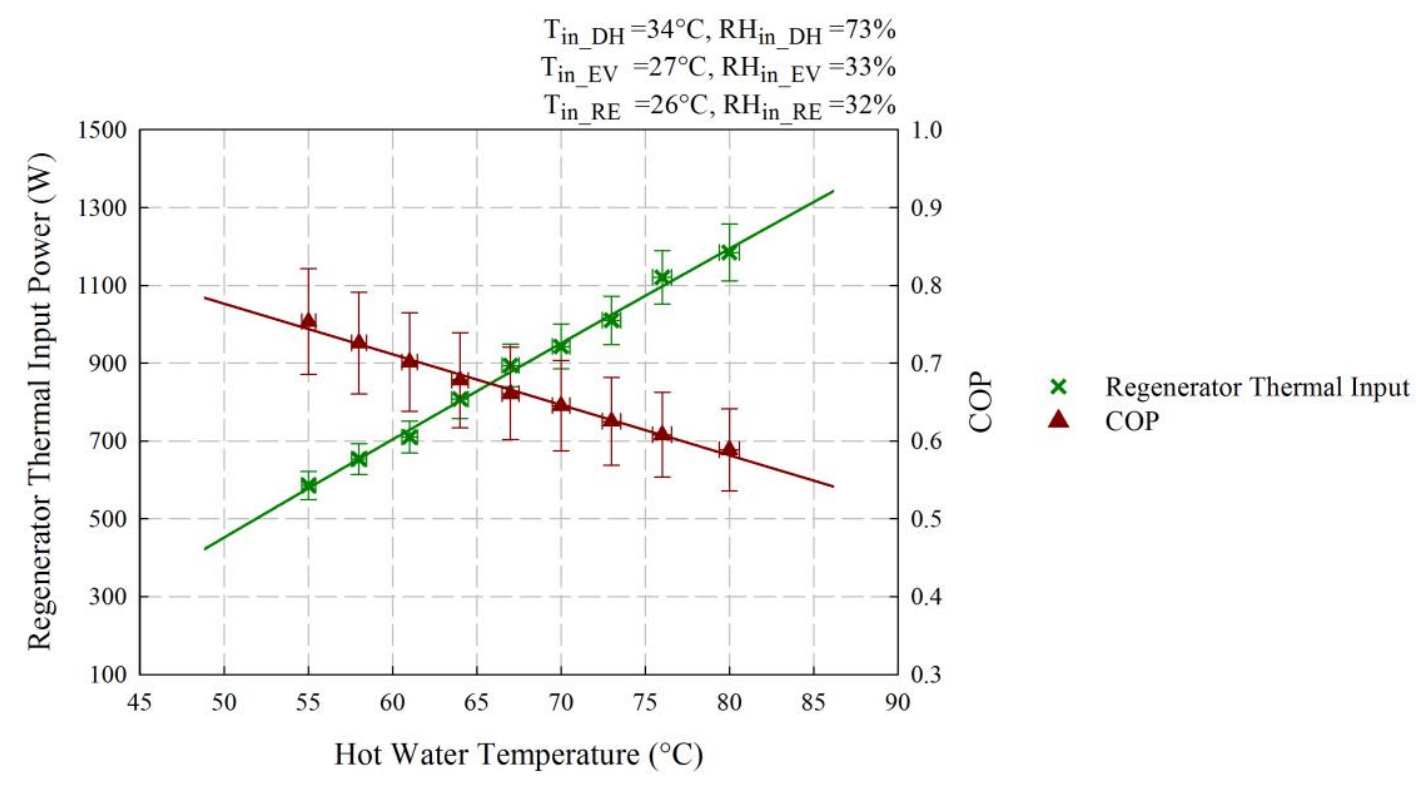

Fig. 18. Influences of hot water temperature on regenerator thermal input power and system COP

\section{Conclusions}

In this study, the performance of a hybrid membrane-based liquid desiccant dehumidification cooling system has been evaluated through experimental work. With $\mathrm{CaCl}_{2}$ solution, the system is feasible for operating in the hot and humid region with efficient independent temperature and humidity controls. Based on the experimental results, the following conclusions are drawn.

- The system dehumidification performance is greatly influenced by the local weather condition, both the moisture removal rate and dehumidification effectiveness increase with inlet air temperature and humidity.

- The dehumidifier cooling output increases with air flow rate while its dehumidification effectiveness deceases simultaneously.

- The regeneration performance improves with air flow rate and hot water temperature, and the required thermal input power increases accordingly. At a solution concentration ratio of $42 \%$, the regenerator moisture addition rate increases by $72.32 \%$ as the hot water temperature rises from $55.0^{\circ} \mathrm{C}$ to $80.0^{\circ} \mathrm{C}$, whereas its thermal input power doubles. 
- To avoid the excessive thermal input power for the desiccant solution regeneration, hot water temperature should be controlled within an appropriate range based on the operative solution concentration ratio.

- The dehumidification, evaporative cooling and overall system performances decrease with cold water temperature, while the supply air temperature increases. The supply air temperature increases from $20.4^{\circ} \mathrm{C}$ to $24.8^{\circ} \mathrm{C}$ as the cold water temperature rises from $10.0^{\circ} \mathrm{C}$ to $20.0^{\circ} \mathrm{C}$.

- The solution concentration ratio has a marked impact on the system performance. The higher the concentration ratio, the better the dehumidification performance, but the regeneration capability is degenerated, and the associated crystallization risk should be noted as well. As the desiccant solution becomes stronger from the concentration ratio of $30 \%$ to $42 \%$, the dehumidification effectiveness improves by 0.37 whereas the regeneration moisture addition rate decreases by $58.38 \%$.

- The system mass balance between the dehumidifier and regenerator is of vital importance for the system steady operation. Appropriate adjustments should be applied for the match between the dehumidification moisture removal rate and regeneration moisture addition rate at a given solution concentration ratio.

- The dehumidification effectiveness of 0.30 and system COP of 0.70 are achieved at a solution concentration of $36 \%$ under the investigated operating condition and the supply air is produced at a temperature of $20.4^{\circ} \mathrm{C}$.

\section{Acknowledgements}

The authors gratefully acknowledge the scholarship support from the Faculty of Engineering of the University of Nottingham. 


\section{References}

[1] V. Vakiloroaya, B. Samali, A. Fakhar, and K. Pishghadam, "A review of different strategies for HVAC energy saving," Energy Conversion and Management, vol. 77, pp. 738-754, 2014.

[2] F. Xiao, G. Ge, and X. Niu, "Control performance of a dedicated outdoor air system adopting liquid desiccant dehumidification," Applied Energy, vol. 88, pp. 143-149, 2011.

[3] K. J. Chua, S. K. Chou, W. M. Yang, and J. Yan, "Achieving better energy-efficient air conditioning - A review of technologies and strategies," Applied Energy, vol. 104, pp. 87-104, 2013.

[4] K. Daou, R. Wang, and Z. Xia, "Desiccant cooling air conditioning: a review," Renewable and Sustainable Energy Reviews, vol. 10, pp. 55-77, 2006.

[5] X. Wang, W. Cai, J. Lu, Y. Sun, and X. Ding, "Heat and Mass Transfer Model for Desiccant Solution Regeneration Process in Liquid Desiccant Dehumidification System," Industrial \& Engineering Chemistry Research, vol. 53, pp. 2820-2829, 2014.

[6] L.-Z. Zhang, "Progress on heat and moisture recovery with membranes: From fundamentals to engineering applications," Energy Conversion and Management, vol. 63, pp. 173-195, 2012.

[7] M. M. Rafique, P. Gandhidasan, and H. M. S. Bahaidarah, "Liquid desiccant materials and dehumidifiers - A review," Renewable and Sustainable Energy Reviews, vol. 56, pp. 179-195, 2016.

[8] A. H. Abdel-Salam and C. J. Simonson, "Annual evaluation of energy, environmental and economic performances of a membrane liquid desiccant air conditioning system with/without ERV," Applied Energy, vol. 116, pp. 134-148, 3/1/ 2014.

[9] L. Mei and Y. J. Dai, "A technical review on use of liquid-desiccant dehumidification for air-conditioning application," Renewable and Sustainable Energy Reviews, vol. 12, pp. 662-689, 2008.

[10] V. Öberg and D. Y. Goswami, "Experimental study of the heat and mass transfer in a packed bed liquid desiccant air dehumidifier," Journal of Solar Energy Engineering, vol. 120, pp. 289-297, 1998.

[11] S. Y. Ahmed, P. Gandhidasan, and A. A. Al-Farayedhi, "Thermodynamic analysis of liquid desiccants," Solar Energy, vol. 62, pp. 11-18, 1998.

[12] P. Gandhidasan, "A simplified model for air dehumidification with liquid desiccant," Solar Energy, vol. 76, pp. 409-416, 2004.

[13] M. T. Zegenhagen, C. Ricart, T. Meyer, R. Kühn, and F. Ziegler, "Experimental Investigation of A Liquid Desiccant System for Air Dehumidification Working With Ionic Liquids," Energy Procedia, vol. 70, pp. 544-551, 2015.

[14] S. Bouzenada, A. N. Kaabi, L. Frainkin, T. Salmon, and A. Léonard, "Experimental Comparative Study on Lithium Chloride and Calcium Chloride Desiccants," Procedia Computer Science, vol. 83, pp. 718-725, 2016.

[15] H. Li, T. Zhang, L. Cong, and X. Xie, "Regeneration methods of liquid desiccant air conditioning system," Heating Ventilating \& Air Conditioning, vol. 43, pp. 105-109, 2013.

[16] R. Qi, L. Lu, and Y. Jiang, "Investigation on the liquid contact angle and its influence for liquid desiccant dehumidification system," International Journal of Heat and Mass Transfer, vol. 88, pp. 210-217, 2015.

[17] Y. Yin, J. Qian, and X. Zhang, "Recent advancements in liquid desiccant dehumidification technology," Renewable and Sustainable Energy Reviews, vol. 31, pp. 38-52, 2014. 
[18] S.-M. Huang and L.-Z. Zhang, "Researches and trends in membrane-based liquid desiccant air dehumidification," Renewable and Sustainable Energy Reviews, vol. 28, pp. 425-440, 2013.

[19] J. Woods, "Membrane processes for heating, ventilation, and air conditioning," Renewable and Sustainable Energy Reviews, vol. 33, pp. 290-304, 2014.

[20] A. T. Mohammad, S. B. Mat, M. Y. Sulaiman, K. Sopian, and A. A. Al-abidi, "Historical review of liquid desiccant evaporation cooling technology," Energy and Buildings, vol. 67, pp. 22-33, 2013.

[21] G. Heidarinejad, M. Bozorgmehr, S. Delfani, and J. Esmaeelian, "Experimental investigation of two-stage indirect/direct evaporative cooling system in various climatic conditions," Building and Environment, vol. 44, pp. 2073-2079, 2009.

[22] Y. Cerci, "A new ideal evaporative freezing cycle," International Journal of Heat and Mass Transfer, vol. 46, pp. 2967-2974, 2003.

[23] J. M. Wu, X. Huang, and H. Zhang, "Theoretical analysis on heat and mass transfer in a direct evaporative cooler," Applied Thermal Engineering, vol. 29, pp. 980-984, 4// 2009.

[24] M. Jradi and S. Riffat, "Experimental investigation of a biomass-fuelled micro-scale tri-generation system with an organic Rankine cycle and liquid desiccant cooling unit," Energy, vol. 71, pp. 80-93, 2014.

[25] M. S. Buker, B. Mempouo, and S. B. Riffat, "Experimental investigation of a building integrated photovoltaic/thermal roof collector combined with a liquid desiccant enhanced indirect evaporative cooling system," Energy Conversion and Management, vol. 101, pp. 239-254, 2015.

[26] Y. Xuan and F. Xiao, "Analysis on energy efficiency of a hybrid liquid desiccant and evaporative cooling system in HongKong," Building Science, vol. 25, pp. 84-63, 2009.

[27] J. Woods and E. Kozubal, "A desiccant-enhanced evaporative air conditioner: Numerical model and experiments," Energy Conversion and Management, vol. 65, pp. 208-220, 2013.

[28] S.-W. Ham, S.-J. Lee, and J.-W. Jeong, "Operating energy savings in a liquid desiccant and dew point evaporative cooling-assisted $100 \%$ outdoor air system," Energy and Buildings, vol. 116, pp. 535-552, 2016.

[29] M. R. Safizadeh, A. Morgenstern, C. Bongs, H.-M. Henning, and J. Luther, "Optimization of a heat assisted air-conditioning system comprising membrane and desiccant technologies for applications in tropical climates," Energy, vol. 101, pp. 5264, 2016.

[30] M. S. Buker and S. B. Riffat, "Recent developments in solar assisted liquid desiccant evaporative cooling technology—A review," Energy and Buildings, vol. 96, pp. 95-108, 2015.

[31] A. H. Abdel-Salam, G. Ge, and C. J. Simonson, "Thermo-economic performance of a solar membrane liquid desiccant air conditioning system," Solar Energy, vol. 102, pp. 56-73, 4// 2014.

[32] S.-M. Huang, L.-Z. Zhang, K. Tang, and L.-X. Pei, "Fluid flow and heat mass transfer in membrane parallel-plates channels used for liquid desiccant air dehumidification," International Journal of Heat and Mass Transfer, vol. 55, pp. 2571-2580, 2012.

[33] T. Elmer, M. Worall, S. Wu, and S. Riffat, "An experimental study of a novel integrated desiccant air conditioning system for building applications," Energy and Buildings, vol. 111, pp. 434-445, 2016.

[34] G. Ge, D. Ghadiri Moghaddam, A. H. Abdel-Salam, R. W. Besant, and C. J. Simonson, "Comparison of experimental data and a model for heat and mass transfer performance of a liquid-to-air membrane energy exchanger (LAMEE) when used for air 
dehumidification and salt solution regeneration," International Journal of Heat and Mass Transfer, vol. 68, pp. 119-131, 2014.

[35] I. P. Koronaki, R. I. Christodoulaki, V. D. Papaefthimiou, and E. D. Rogdakis, "Thermodynamic analysis of a counter flow adiabatic dehumidifier with different liquid desiccant materials," Applied Thermal Engineering, vol. 50, pp. 361-373, 2013.

[36] W. Y. Saman and S. Alizadeh, "An experimental study of a cross-flow type plate heat exchanger for dehumidification/cooling," Solar Energy, vol. 73, pp. 59-71, 2002.

[37] S. A. Abdul-Wahab, Y. H. Zurigat, and M. K. Abu-Arabi, "Predictions of moisture removal rate and dehumidification effectiveness for structured liquid desiccant air dehumidifier," Energy, vol. 29, pp. 19-34, 2004.

[38] A. Melinder, Thermophysical Properties of Aqueous Solutions Used as Secondary Working Fluids [Elektronisk resurs]. Stockholm: KTH, 2007.

[39] S. Liu, "A novel heat recovery/desiccant cooling system," PhD, Architecture and Built Environment, University of Nottingham, 2008.

[40] S. Bell, "Measurement Good Practice Guide No. 11 (Issue 2)," A Beginner's Guide to Uncertainty of Measurement. National Physical Laboratory Teddington, Middlesex, United Kingdom, 2001.

[41] P. T. Tsilingiris, "Thermophysical and transport properties of humid air at temperature range between 0 and $100{ }^{\circ} \mathrm{C}$," Energy Conversion and Management, vol. 49, pp. 1098$1110,5 / / 2008$.

[42] L. A. Cisternas and E. J. Lam, "An analytic correlation for the vapour pressure of aqueous and non-aqueous solutions of single and mixed electrolytes. Part II. Application and extension," Fluid Phase Equilibria, vol. 62, pp. 11-27, 1991.

[43] S. Bouzenada, A. N. Kaabi, L. Fraikin, and A. Léonard, "Experimental Study on dehumidification/regeneration of Liquid Desiccant: $\mathrm{LiBr}$ Solution," Procedia Computer Science, vol. 32, pp. 673-680, 2014.

[44] A. H. Abdel-Salam, G. Ge, and C. J. Simonson, "Performance analysis of a membrane liquid desiccant air-conditioning system," Energy and Buildings, vol. 62, pp. 559-569, 2013.

[45] Z. Yang, B. Lin, K. Zhang, and Z. Lian, "Experimental study on mass transfer performances of the ultrasonic atomization liquid desiccant dehumidification system," Energy and Buildings, vol. 93, pp. 126-136, 2015.

[46] M. M. Hammad, R. I. El-Ghanam, R. Y. Sakr, and S. S. Ayad, "Theoretical Study for Compact Liquid Desiccant Dehumidifier/Regenerator System," in The Al-Azhar Engineering Tenth International Conference, Cairo, 2008, pp. 352-378.

[47] Y. Yin, S. Li, X. Zhang, and D. Peng, "Feasibility and performance analysis of a desiccant solution regenerator using hot air," Energy and Buildings, vol. 43, pp. 10971104, 2011.

[48] J. Liu, T. Zhang, X. Liu, and J. Jiang, "Experimental analysis of an internallycooled/heated liquid desiccant dehumidifier/regenerator made of thermally conductive plastic," Energy and Buildings, vol. 99, pp. 75-86, 2015.

[49] N. Fumo and D. Y. Goswami, "Study of an aqueous lithium chloride desiccant system: Air dehumidification and desiccant regeneration," Solar Energy, vol. 72, pp. 351-361, 2002. 